\title{
Helicopter-borne observations of the continental background aerosol in combination with remote sensing and ground-based measurements
}

\author{
Sebastian Düsing ${ }^{1}$, Birgit Wehner ${ }^{1}$, Patric Seifert ${ }^{1}$, Albert Ansmann ${ }^{1}$, Holger Baars ${ }^{1}$, Florian Ditas ${ }^{1,2}$, \\ Silvia Henning ${ }^{1}$, Nan $\mathrm{Ma}^{1}$, Laurent Poulain ${ }^{1}$, Holger Siebert ${ }^{1}$, Alfred Wiedensohler ${ }^{1}$, and Andreas Macke ${ }^{1}$ \\ ${ }^{1}$ Leibniz Institute for Tropospheric Research (TROPOS), 04318 Leipzig, Germany \\ ${ }^{2}$ Multiphase Chemistry Department, Max Planck Institute for Chemistry, P.O. Box 3060, 55020, Mainz, Germany
}

Correspondence: Sebastian Düsing (duesing@tropos.de)

Received: 30 June 2017 - Discussion started: 20 July 2017

Revised: 8 November 2017 - Accepted: 24 November 2017 - Published: 31 January 2018

\begin{abstract}
This paper examines the representativeness of ground-based in situ measurements for the planetary boundary layer (PBL) and conducts a closure study between airborne in situ and ground-based lidar measurements up to an altitude of $2300 \mathrm{~m}$. The related measurements were carried out in a field campaign within the framework of the HighDefinition Clouds and Precipitation for Advancing Climate Prediction $\left(\mathrm{HD}(\mathrm{CP})^{2}\right)$ Observational Prototype Experiment (HOPE) in September 2013 in a rural background area of central Europe.

The helicopter-borne probe ACTOS (Airborne Cloud and Turbulence Observation System) provided measurements of the aerosol particle number size distribution (PNSD), the aerosol particle number concentration (PNC), the number concentration of cloud condensation nuclei (CCN-NC), and meteorological atmospheric parameters (e.g., temperature and relative humidity). These measurements were supported by the ground-based $3+2$ wavelength polarization lidar system Polly ${ }^{\mathrm{XT}}$, which provided profiles of the particle backscatter coefficient $\left(\sigma_{\mathrm{bsc}}\right)$ for three wavelengths (355, 532 , and $1064 \mathrm{~nm})$. Particle extinction coefficient $\left(\sigma_{\text {ext }}\right)$ profiles were obtained by using a fixed backscatter-to-extinction ratio (also lidar ratio, LR). A new approach was used to determine profiles of CCN-NC for continental aerosol. The results of this new approach were consistent with the airborne in situ measurements within the uncertainties.

In terms of representativeness, the PNSD measurements on the ground showed a good agreement with the measurements provided with ACTOS for lower altitudes. The ground-based measurements of PNC and CCN-NC are rep-
\end{abstract}

resentative of the PBL when the PBL is well mixed. Locally isolated new particle formation events on the ground or at the top of the PBL led to vertical variability in the cases presented here and ground-based measurements are not entirely representative of the PBL.

Based on Mie theory (Mie, 1908), optical aerosol properties under ambient conditions for different altitudes were determined using the airborne in situ measurements and were compared with the lidar measurements. The investigation of the optical properties shows that on average the airbornebased particle light backscatter coefficient is $50.1 \%$ smaller for $1064 \mathrm{~nm}, 27.4 \%$ smaller for $532 \mathrm{~nm}$, and $29.5 \%$ smaller for $355 \mathrm{~nm}$ than the measurements of the lidar system. These results are quite promising, since in situ measurement-based Mie calculations of the particle light backscattering are scarce and the modeling is quite challenging. In contrast, for the particle light extinction coefficient we found a good agreement. The airborne-based particle light extinction coefficient was just $8.2 \%$ larger for $532 \mathrm{~nm}$ and $3 \%$ smaller for $355 \mathrm{~nm}$, for an assumed LR of $55 \mathrm{sr}$. The particle light extinction coefficient for $1064 \mathrm{~nm}$ was derived with a LR of $30 \mathrm{sr}$. For this wavelength, the airborne-based particle light extinction coefficient is $5.2 \%$ smaller than the lidar measurements. For the first time, the lidar ratio of $30 \mathrm{sr}$ for $1064 \mathrm{~nm}$ was determined on the basis of in situ measurements and the LR of $55 \mathrm{sr}$ for 355 and $532 \mathrm{~nm}$ wavelength was reproduced for European continental aerosol on the basis of this comparison. Lidar observations and the in situ based aerosol optical properties agree within the uncertainties. However, our observations indicate that a determination of the PNSD for a large 
size range is important for a reliable modeling of aerosol particle backscattering.

\section{Introduction}

Aerosol particles are a ubiquitous constituent of the Earth's atmosphere (Vaughan and Cracknell, 2013). Their sources are manifold, reaching from natural ones such as the oceans, deserts, and the biosphere to anthropogenic ones such as biomass-burning activity, transportation, agricultural, and resuspended dust or industrial pollution (Pöschl, 2005; Seinfeld and Pandis, 2006). Once aerosol particles are formed from precursor gases or suspended in air, they can be carried over hundreds to thousands of kilometers before they are removed from the atmosphere by dry or wet deposition. The lifetime in the boundary layer counts from hours to approximately 2 weeks (Seinfeld and Pandis, 2006). During their residence time in the atmosphere, aerosol particles have impacts on atmospheric chemistry, cloud formation, and microphysics (change of cloud albedo; Twomey et al., 1977) as well as on the radiation budget by changing cloud albedo and cloud lifetime (Twomey et al., 1977). Consequently, aerosol particles have both a natural and an anthropogenic influence on weather and climate (IPCC, 2013). The direct climatic effect of aerosols is based on their radiative cooling or heating of the atmosphere due to scattering and absorption of solar radiation (Bohren and Huffman, 1983; Chauvigné et al., 2016; Seinfeld and Pandis, 2006). The estimate of the radiative forcing by aerosol-radiation interaction of $-0.35 \mathrm{~W} \mathrm{~m}^{-2}$ is very uncertain within the borders of -0.85 to $+0.15 \mathrm{~W} \mathrm{~m}^{-2}$ (IPCC, 2013). The type of aerosol is important in this consideration. For instance, inorganic salts such as sulfate or nitrate aerosols lead to an estimated negative radiative forcing of $-0.4 \mathrm{~W} \mathrm{~m}^{-2}$ and therefore have a cooling effect on the atmosphere. The absorbing behavior of black carbon (BC) particles in contrast warms the atmosphere and leads to a positive radiative forcing of approximately $+0.71 \mathrm{~W} \mathrm{~m}^{-2}$ (90\% uncertainty bounds from +0.08 to $+1.27 \mathrm{~W} \mathrm{~m}^{-2}$ ) (Bond et al., 2013). These estimates are subject to uncertainties of 50 to $100 \%$. A considerable fraction of this uncertainty arises from the highly uncertain knowledge of the vertical distribution of the aerosol particles in the atmosphere. As an example, Zarzycki and Bond (2010) found that small changes of the vertical BC distribution at cloud interfaces lead to a change in global radiative forcing by 5 to $10 \%$. Samset et al. (2013) furthermore stated that at least $20 \%$ of the uncertainty in radiative forcing due to the $\mathrm{BC}$ is caused by the diversity of the modeled $\mathrm{BC}$ particle mass vertical distribution. For aerosol types which contain hydrophilic aerosol compounds such as inorganic salts, the vertical profile of the relative humidity $(\mathrm{RH})$ also needs to be known to determine the actual particle hygroscopic proper- ties, as well as to account for changes in the scattering properties due to hygroscopic-growth effects (Pilinis et. al, 1995).

In particular, aerosol particle properties in the planetary boundary layer (PBL) require a thorough characterization, because the majority of the global aerosol mass is emitted, formed (Rosati et al., 2016b), and also trapped there (Summa et al., 2013). For instance, for a residential area in the Czech Republic, Hovorka et al. (2016) found aerosol particle mass concentrations at the top of the PBL to be 5 times larger than just above the PBL $\left(50 \mu \mathrm{g} \mathrm{m}^{-3}\right.$ in contrast to $\left.10 \mu \mathrm{g} \mathrm{m}^{-3}\right)$.

In order to derive the aerosol radiative forcing in an atmospheric air column, profiles of the aerosol particle light extinction coefficient $\left(\sigma_{\text {ext }}\right)$, which is the sum of the aerosol particle light absorption and scattering coefficient, are a feasible measure. Height-resolved aerosol particle light extinction coefficients can be obtained either by airborne in situ measurements or with remote sensing techniques such as lidar. Ground-based remote sensing observations with lidar are suitable to derive long-term temporally resolved profiles of the mentioned coefficients detecting the backscattered light of the total aerosol particle population in its ambient state (Baars et al., 2016; Engelmann et al., 2016). However, lidar measurements are restricted to the retrieval of the total aerosol particle light extinction coefficient. The separation into the contributions of scattering and absorption relies on complex inversion schemes, which are restricted to nighttime observations, long averaging times, and rather low vertical resolution (Müller et al., 1999, 2000). Recently, novel approaches based on the combination of daytime lidar observations with sun photometer measurements of columnintegrated aerosol particle light scattering properties were developed, which allow estimating the contributions of absorption and scattering. This is for instance the case for the Generalized Aerosol Retrieval from Radiometer and Lidar Combined data (GARRLiC) algorithm (Lopatin et al., 2013). However, these techniques are in general still based on column-integrated measurements and thus are still subject to considerable uncertainties when the aerosol load is low (Bond et al., 2013). Furthermore, these methods are limited to certain conditions, such as the requirements of cloud-free conditions and high aerosol optical depths of at least 0.5 at a wavelength of $440 \mathrm{~nm}$ (Dubovik et al., 2002).

A benefit of airborne and ground-based in situ measurements is that they allow us to obtain high-quality measurements of the aerosol particle number size distribution (PNSD), optical properties of the aerosol, and consequently the relationship between aerosol microphysical properties, chemical properties, and resulting aerosol particle light absorption, scattering, and extinction coefficients. In particular, a large number of long-term observations exist on the ground. For instance, in Germany the German Ultra-fine Aerosol Network (GUAN; Birmili et al., 2016) is operative. The Global Atmosphere Watch (GAW) network includes a large number of operating stations (http://www.wmo.int/pages/prog/arep/ gaw/measurements.html). Disadvantageously, with ground- 
based in situ measurements no vertically resolved information about aerosol properties is available, which is needed to ascertain aerosol-cloud interaction (Breon, 2006). Without vertically resolved information, ground-based observations are usually assumed to be representative of the entire PBL and even ground-based measurements are often extrapolated to larger scales (Väänänen et al., 2016). Thus, as stated, e.g., by Rosati et al. (2016a), it is of scientific interest to better understand whether ground-based in situ measurements can be used to investigate aerosol properties, in particular their optical properties, for elevated atmospheric layers. This general approach leads to biases in modeling aerosol radiative effects. In particular, indirect effects indicated by anthropogenic emitted aerosol particles acting as cloud condensation nuclei $(\mathrm{CCN})$ contribute strongest to the uncertainty in aerosol total radiative forcing (IPCC, 2007; Schwartz et al., 2010). Recently, Mamouri and Ansmann (2016) provided a method to derive $\mathrm{CCN}$ number concentration (CCN-NC) profiles from lidar measurements. This method is the first step to evaluate CCN-NC's profiles with ground-based techniques. However, this method produces significant uncertainties of factor 2 to 3 .

Opposed to the ground-based in situ measurements, airborne measurements, such as from aircraft (Wex et al., 2002), tethered-balloon systems (Ferrero et al., 2014; Mazzola et al., 2016; Ran et al., 2016), zeppelin systems (Rosati et al., 2016a, b), unmanned aerial systems (Altstädter et al., 2015), or helicopter-borne payload (Siebert et al., 2006), are capable to provide spatiotemporal highly resolved measurements of optical and microphysical aerosol particle properties in a vertical and horizontal manner. However, these observations are rather expensive in cost and limited in time.

Disadvantageously, both airborne and ground-based in situ measurements alter the humidity state of the aerosol. Therefore, the aerosol is often dried before the particle properties are characterized to achieve comparability between different measurements (Wiedensohler et al., 2012). A comparability with lidar measurements can be achieved by simulating the environmental condition (e.g., size) of the particles. The hygroscopic properties of the particles that can be either measured or calculated are relevant in this context. The parameterization by Petters et al. (2007) is for this purpose a useful approach to ascertain the hygroscopic growth of the aerosol particles on the basis of their hygroscopicity parameter $(\kappa)$.

Within the scope of this article, two of the abovementioned challenges are addressed by means of sophisticated closure studies: (a) ground-based in situ observations were compared to airborne in situ observations to investigate the representativeness of ground-based in situ measurements for the planetary boundary layer and (b) airborne in situ observations were compared to ground-based remote sensing to cross-check assumptions made in lidar remote sensing. These were corroborated in the frame of the $\mathrm{HD}(\mathrm{CP})^{2}$ Observational Prototype Experiment HOPE (Macke et al., 2017) at the central European research observatory Melpitz, Ger- many. In particular, lidar-based aerosol optical properties are compared to respective values obtained from airborne in situ measurements, based on modeled optical properties for the regional background aerosol under consideration of the hygroscopic growth of the aerosol particles. We focus on the aerosol particle light backscatter coefficient $\left(\sigma_{\mathrm{bsc}}\right)$, since this is the directly measured property of a lidar system. Its conversion from the extinction-to-backscatter ratio (lidar ratio, LR) to the particle light extinction coefficient is also the subject of this investigation.

Additionally, the representativeness of ground-based observations of CCN-NC and thereby directly connected the aerosol hygroscopicity, particle number concentration (PNC), and the PNSD for different conditions in the PBL are studied by comparing the airborne in situ measurements with the observations at Melpitz. Furthermore, CCN-NC profiles derived with the approach of Mamouri and Ansmann (2016) are compared with in situ measured CCN-NCs for $0.2 \%$ supersaturation.

The results of this work are presented as follows. Section 2 describes the experiment with all instruments used. In doing so, we will deal separately with the ground and airborne measurements. A description of the meteorological conditions on the measurement days and an explanation of the algorithm for determining the optical properties of the aerosol under ambient conditions are described in Sect. 3. Section 4 uses case studies to clarify the representativeness of groundbased measurements for the planetary boundary layer. Furthermore, a closure between lidar measurements and airborne measurements is shown. Optical and microphysical aerosol properties $(\mathrm{CCN})$ are discussed. Finally, the results are summarized in Sect. 5.

\section{Experiment}

HOPE-Melpitz was one of two field experiments within the scope of the "High Definition Clouds and Precipitation for advancing climate prediction" project (see http://www. hdcp2.eu). The project's aims have been to reduce uncertainties in the representation of cloud and precipitation in atmospheric models (detailed information for HOPE is given in Macke et al., 2017).

HOPE-Melpitz took place between 9 and 27 September 2013, at the central European research observatory Melpitz, Saxony, Germany ( $51^{\circ} 32^{\prime}$ N, $12^{\circ} 56^{\prime}$ E; 84 ma.s.1.). Melpitz is located in a rural area, $44 \mathrm{~km}$ northeast of Leipzig. The approximate distance to the Baltic Sea in the north is $400 \mathrm{~km}, 500 \mathrm{~km}$ to the North Sea, and $1000 \mathrm{~km}$ to the Atlantic Ocean. The TROPOS field observatory Melpitz is situated in a plain open landscape, bound by the Ore Mountains to the further south, Berlin to the north, Leipzig to the west, and Polish industrial areas to the east. The measurements are therefore representative of the central European regional background aerosol. 


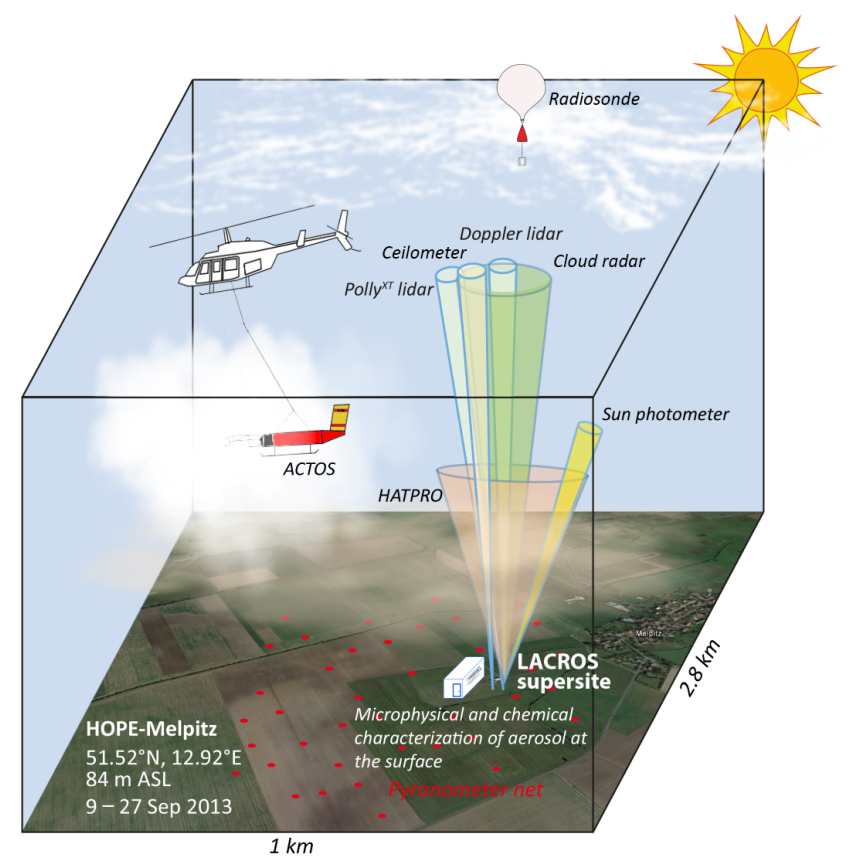

Figure 1. Scheme of the measurement setup used during HOPEMelpitz (from Macke et al., 2017).

The Melpitz Observatory is included in several observational networks and setups, such as LACROS (Leipzig Aerosol and Cloud Remote Observations System), GUAN, ACTRIS (Aerosols, Clouds and Trace gases Research Infrastructure; www.actris.eu), and GAW. A ground stock of instruments is implemented for permanent, high-quality, longterm measurements, including PNSD, CCN-NC, aerosol particle light scattering and absorption, and aerosol chemical composition. A detailed description of this measurement site is given in Spindler et al. (2013, 2010).

In addition to the continuously operating instrumentation, several ground-based remote sensing instruments (e.g., the Raman lidar system Polly ${ }^{X T}$; Engelmann et al., 2016) were installed during the intensive campaign period, providing a detailed overview of the atmospheres constitution (see Fig. 1). These measurements were complimented by the helicopter-borne payload ACTOS (Airborne Cloud and Turbulence Observation System; Siebert et al., 2006) inferring microphysical aerosol particle and cloud properties with a high spatiotemporal resolution. Figure 1 shows a scheme of the installed instrumentation during the HOPE-Melpitz campaign.

The following section will provide a detailed description of the instrumentation used within the scope of this work.

\subsection{Ground-based in situ instrumentation}

\subsubsection{Particle number size distribution}

The PNSD was derived using two instruments under controlled dry conditions as recommended in Wiedensohler et al. (2012). A dual mobility particle size spectrometer (TROPOS-type T-MPSS; Birmili et al., 1999) was used to measure the PNSD in the mobility diameter $D_{\mathrm{em}}$ range from 3 to $800 \mathrm{~nm}$. Each scan of the PNSD lasts $10 \mathrm{~min}$ and is available every $20 \mathrm{~min}$. An aerodynamic particle size spectrometer (model APS-3320, TSI Inc., Shoreview, MN, USA) was employed to determine the PNSD in aerodynamic diameter $D_{\mathrm{a}}$ range from 0.8 to $10 \mu \mathrm{m}$, also with a time resolution of $10 \mathrm{~min}$. The T-MPSS PNSD was derived using the inversion algorithm of Pfeifer et al. (2014) and corrected with respect to internal and inlet diffusional losses, using the method of "equivalent pipe length" (Wiedensohler et al., 2012).

Both size distributions were merged to a continuous distribution after converting the $D_{\mathrm{a}}$ of the APS to $D_{\mathrm{em}}$ by using

$D_{\mathrm{em}}=D_{\mathrm{a}} \sqrt{\frac{\chi \rho_{0}}{\rho_{\mathrm{a}}}}$

according to DeCarlo et al. (2004), whereby the aerosol particle density is assigned by $\rho_{\mathrm{a}}$ and $\rho_{0}$ is the standard density of $1.0 \mathrm{~g} \mathrm{~cm}^{-3}$. The dynamic shape factor is represented by $\chi$. In this study we assumed an effective aerosol particle density of $1.6 \mathrm{~g} \mathrm{~cm}^{-3}$, according to Ma et al. (2014), for the fine-mode aerosol. The effective density combines the particle density and dynamic shape factor.

\subsubsection{Chemical composition}

This section introduces instruments used for measuring the aerosol particle composition, including non-refractory particulate matter and water-insoluble BC.

\section{Non-refractory chemical compounds}

In this study, a dataset of the continuously running Quadrupole Aerosol Chemical Speciation Monitor (QACSM, Aerodyne Res. Inc, ARI, Billerica, MA.; Ng et al., 2011) was used. The Q-ACSM detects non-refractory particulate matter in the fine regime (NR-PM1) that vaporizes at around $600^{\circ} \mathrm{C}$ with a time resolution of about $25 \mathrm{~min}$. The included mass spectrometer separates the vaporized material into $\mathrm{SO}_{4}^{-2}, \mathrm{NO}^{-3}, \mathrm{NH}^{+4}$, and organics ( $\mathrm{Ng}$ et al., 2011). A detailed description of the instrument is provided by $\mathrm{Ng}$ et al. (2011) and Fröhlich et al. (2015).

Based on these ion measurements, the chemical composition of the aerosol particles itself was derived by a simple ion pairing scheme published by Gysel et al. (2007). Although the measurements can be influenced by water-insoluble hydrocarbons, we consider the species of the aerosol compounds derived with the Q-ACSM to be water soluble, since 
Table 1. Hygroscopicity $\kappa$ and density $\rho$ of each considered aerosol particle compound.

\begin{tabular}{lrr}
\hline Component & $\kappa_{i}$ & $\rho_{i}\left[\mathrm{~g} \mathrm{~cm}^{-3}\right]$ \\
\hline eBC & $0^{1}$ & $1.5^{4}$ \\
Organics & $0.1^{2}$ & $1.27^{3}$ \\
$\mathrm{NH}_{4} \mathrm{NO}_{3}$ & $0.67^{2}$ & $1.735^{5}$ \\
$\mathrm{H}_{2} \mathrm{SO}_{4}$ & $0.9^{2}$ & $1.84^{5}$ \\
$\mathrm{NH}_{4} \mathrm{HSO}_{4}$ & $0.61^{2}$ & $1.78^{5}$ \\
$\left(\mathrm{NH}_{4}\right)_{2} \mathrm{SO}_{4}$ & $0.61^{2}$ & $1.76^{5}$ \\
\hline
\end{tabular}

${ }^{1}$ Wu et al. (2013); assumed to be $0 .{ }^{2}$ Zaveri

et al. (2010). ${ }^{3}$ Ma et al. (2014). ${ }^{4}$ Cross

et al. (2007). ${ }^{5}$ Lin et al. (2014).

Crippa et al. (2014) have found that all over in Europe the mass fraction of hydrocarbons in organic compounds is $11 \pm 6 \%$. The major mass fraction of the non-refractory chemical compounds are in $\mathrm{PM}_{1}$ and are thus also representative of $\mathrm{PM}_{2.5}$.

\section{Equivalent black carbon (eBC)}

The Multi-Angle Absorption Photometer (MAAP; model 5012, Thermo Scientific) was used to derive the equivalent mass concentration of the non-water-soluble eBC for $\mathrm{PM}_{10}$ aerosol. MAAP determines the aerosol particle light absorption coefficient $\left(\sigma_{\mathrm{abs}}\right)$ by measuring the attenuation of light at a wavelength of $637 \mathrm{~nm}$ (Müller et al., 2011) due to particulate matter deposited on a filter band and by reflected light at two angles. The eBC particle mass concentration is calculated by a mass absorption cross section of $6.6 \mathrm{~m}^{2} \mathrm{~g}^{-1}$. With the assumption that all of the measured $\mathrm{eBC}$ is elemental carbon (EC), according to Spindler et al. (2013) and Poulain et al. (2014), we assume here that $\mathrm{PM}_{1}$ aerosol contains $90 \%$ of the $\mathrm{PM}_{10} \mathrm{eBC}(\mathrm{EC})$ mass derived with the MAAP.

The particle volume concentration and as a consequence thereof the volume fraction of each aerosol particle compound was calculated by using the density of the individual species (see Table 1). Like Tsekeri et al. (2017), we assumed that the aerosol particles in $\mathrm{PM}_{2.5}$ and $\mathrm{PM}_{1}$ had the similar chemical composition since no highly time-resolved chemical composition measurements for coarse-mode aerosol particles were available during the campaign.

\subsubsection{Cloud condensation nuclei number concentration}

Ground-based monodisperse CCN-NC measurements at Melpitz are part of the standard measurements within the ACTRIS network. A stream-wise thermal gradient cloud condensation nuclei counter $(\mathrm{CCNc}$; model CCN100, Droplet Measurement Technologies, Boulder, USA; Roberts and Nenes, 2005) is operated to investigate the supersaturation-dependent growth activation of particles.
Table 2. Summary of takeoff and landing times of the respective flights of HOPE.

\begin{tabular}{lcc}
\hline $\begin{array}{l}\text { Flight } \\
\text { [yyyymmdd a/b] }\end{array}$ & $\begin{array}{c}\text { Takeoff } \\
\text { [UTC] }\end{array}$ & $\begin{array}{c}\text { Landing } \\
\text { [UTC] }\end{array}$ \\
\hline 20130912a & $13: 02$ & $13: 41$ \\
$20130913 \mathrm{a}$ & $08: 51$ & $10: 36$ \\
$20130914 \mathrm{a}$ & $08: 19$ & $10: 16$ \\
$20130914 \mathrm{~b}$ & $12: 05$ & $13: 54$ \\
$20130917 \mathrm{a}$ & $08: 36$ & $10: 31$ \\
$20130921 \mathrm{a}$ & $11: 15$ & $13: 07$ \\
$20130922 \mathrm{a}$ & $08: 56$ & $10: 48$ \\
$20130927 \mathrm{a}$ & $08: 08$ & $10: 10$ \\
\hline
\end{tabular}

The relative uncertainty of the supersaturation can be estimated to be within $10 \%$ (Henning et al., 2014).

Briefly, the measurement method is as follows: a differential mobility analyzer (DMA) selects aerosol particles according to their mobility diameter, which are then counted in total number at this size with a particle counter (model CPC-3010, TSI Inc., Shoreview, MN, USA; $\left.N_{\text {tot }}\left(D_{\mathrm{p}}\right)\right)$ and at a certain water supersaturation with the $\mathrm{CCNc}\left(N_{\mathrm{CCN}}\left(D_{\mathrm{p}}\right)\right)$. The size-dependent activated fraction $(\mathrm{AF})$ was calculated by the ratio of the PNC of activated particles and the total PNC of a certain size measured after the DMA. The AF was derived on the basis of diameter scans in the size range from 20 to $440 \mathrm{~nm}$ (dry diameter of the aerosol particles) and for different supersaturations in the range from 0.1 to $0.7 \%$. With a Gaussian error function the AF can be fitted according to

$\mathrm{AF}=\frac{a+b}{2}\left[1+\operatorname{erf}\left(\frac{D-D_{\mathrm{c}}}{\sigma \sqrt{2}}\right)\right]$,

where $a$ and $b$ denote the upper and the lower limit for the calculation of the critical diameter $D_{\mathrm{c}}$ (Henning et al., 2014). $D_{\mathrm{c}}$ is the diameter from which on $50 \%$ of the particles are activated to droplets. With the single-parameter parameterization by Petters and Kreidenweis (2007) and $D_{\mathrm{c}}$ from Eq. (2) the hygroscopicity parameter can be derived by using

$\kappa=\frac{4 A^{3}}{27 D_{\mathrm{c}}^{3}(\ln S S)^{2}}$,

with

$A=\frac{4 \sigma_{\mathrm{s} / \mathrm{a}} M_{\mathrm{W}}}{R T \rho_{\mathrm{W}}}$.

In Eqs. (3) and (4), $\rho_{\mathrm{W}}$ is the density of water, $M_{\mathrm{W}}$ the molecular weight of the water, SS the supersaturation inside the $\mathrm{CCNc}, \sigma_{\mathrm{s} / \mathrm{a}}=0.072 \mathrm{~J} \mathrm{~m}^{-2}$ the surface tension of the solution, $R=8.314 \mathrm{~J} \mathrm{~mol}^{-1} \mathrm{~K}^{-1}$ the universal gas constant, and $T$ the temperature.

\subsection{Airborne measurements}

ACTOS (Siebert et al., 2006) was deployed at a $140 \mathrm{~m}$ long rope below a helicopter (Siebert et al., 2006). Airborne in 
situ measurements were performed on 7 days between 12 and 28 September 2013. Each flight lasted typically between 90 and $120 \mathrm{~min}$ (see Table 2). The measurement flights started at the small airport of Beilrode approximately $11 \mathrm{~km}$ ton the northeast of Melpitz (see Fig. 2). The flights were usually performed as follows: after the arrival in the measurement area of Melpitz, a vertical profile up to an altitude of $2300 \mathrm{~m}$ aboveground was performed first to determine the layer structure of the atmosphere. In a second step, legs of up to 20 min with constant heights were carried out. In this study, these parts are indicated as horizontal legs.

ACTOS includes instruments to provide meteorological parameters, including RH and temperature $T$ with a time resolution of $100 \mathrm{~Hz}$. ACTOS probes the atmosphere with a true air speed of around $20 \mathrm{~ms}^{-1}$. Real-time data allow the onboard scientist to observe actual atmospheric conditions and to adjust the flight pattern accordingly.

In addition to the meteorological sensors, also the PNC and PNSD were determined on ACTOS (Wehner et al., 2010, 2015; Ditas et al., 2012). According to recommendations given in Wiedensohler et al. (2012), the aerosol flow was dried, using a silca-based diffusion dryer to obtain a RH below $40 \%$. A mobility and an optical particle size spectrometer (MPSS and OPSS) were employed to determine the PNSD in the size range of $8 \mathrm{~nm}$ to $2.8 \mu \mathrm{m}$. In the further course of this work, PNSD connotes dry-state PNSD.

A TROPOS-type MPSS measured the PNSD in the size range from 8 to $226 \mathrm{~nm}$ (mobility diameter $D_{\mathrm{em}}$ ) with a time resolution of $120 \mathrm{~s}$. A Grimm OPSS (model 1.129 (skyOPC); Grimm Aerosol Technik, Ainring, Germany) was used to obtain the PNSD in the size range from $356 \mathrm{~nm}$ to $2.8 \mu \mathrm{m}$ (optical diameter $D_{\mathrm{o}}$ ) with time resolution of $1 \mathrm{~s}$. A full PNSD was derived by combining each of the MPSS-PNSD with the respective $120 \mathrm{~s}$ median OPSS-PNSD. This setup causes uncertainties in integration-based aerosol properties, such as the total aerosol particle number concentration, because integrals of the non-observed size range were approximated with a trapezoid.

The MPSS consists of (a) a bipolar diffusion charger to bring the aerosol particle population into the bipolar charge equilibrium (Fuchs, 1963; Wiedensohler, 1988), (b) a TROPOS-type DMA (Hauke-type, short) to select the aerosol particles with respect to their electrical mobility, and (c) a condensation particle counter (CPC, model 3762A, TSI Inc., Shoreview, MN, USA) with a lower detection efficiency diameter of $8 \mathrm{~nm}$ and a counting efficiency of $10 \%$. This setup was also used in Wehner et al. (2010) and Ditas et al. (2012). The measured raw PNSD of the MPSS was processed using the inversion algorithm of Pfeifer et al. (2014) by enhancing the inversion with the PNSD obtained with the OPSS. The PNSD was also corrected with respect to the sampling efficiency of the inlet according to Kulkarni et al. (2011). With a sampling angle $\alpha_{\mathrm{s}}=85^{\circ}$ and a volume flow of $3.7 \mathrm{~L} \mathrm{~min}^{-1}$ the inlet had a theoretical upper $50 \%$ cutoff aerodynamic diameter of approximately $D_{\mathrm{p}, 50}=2 \mu \mathrm{m}$.

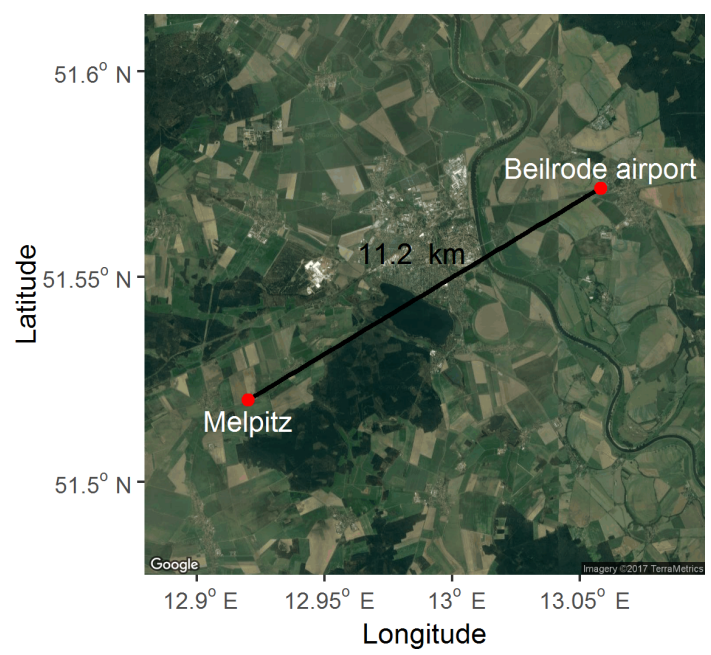

Figure 2. Location of the measurement sites Melpitz and the airfield in Beilrode. Map from https://www.google.com/maps.

Furthermore, the measured PNC of ultrafine particles is influenced by diffusional losses. Following Kulkarni et al. (2011) and Wiedensohler et al. (2012) these losses were corrected using the method of the "equivalent pipe length". A second CPC, identical to the CPC consisting in the MPSS, was installed to determine PNC $\left(N_{\mathrm{CPC}}\right)$ of the aerosol sampled through the same inlet of the MPSS with a temporal resolution of $1 \mathrm{~Hz}$ and a lower cutoff of $\sim 8 \mathrm{~nm}$. This second CPC also allowed us to evaluate the quality of the PNSD measurements.

Since the Grimm OPSS was not calibrated with spherical polystyrene latex (PSL) particle size standards, it was not possible to adjust the optical PNSD with a refractive index typical for the atmospheric aerosol in Germany. Therefore, the here used OPSS measurements deviate from the "real" PNSD to some extent.

Furthermore, the polydisperse CCN-NC was determined with a mini cloud condensation nuclei counter ( $\mathrm{mCCNc}$, custom built by Gregory C. Roberts) also installed on ACTOS. The CCN-NC derived with the mCCNc $\left(N_{\mathrm{CCN}, \mathrm{mCCNc}}\right)$ was measured at a supersaturation of $0.2 \%$ (within an accuracy of $10 \%$; Henning et al., 2014).

\subsection{Ground-based remote sensing}

A $3+2$ wavelength (three channels for backscatter and two channels for extinction) polarization lidar system, called Polly ${ }^{\mathrm{XT}}$ and introduced by Engelmann et al. (2016), was used to evaluate vertical profiles of optical aerosol properties. In particular, the particle backscatter coefficient $\sigma_{\mathrm{bsc}}$ was derived for 355, 532, and $1064 \mathrm{~nm}$. Furthermore, Polly XT is capable of deriving the $\sigma_{\text {ext }}$ for 355 and $532 \mathrm{~nm}$. In this paper, aerosol particle optical properties derived with the lidar system are assigned with the subscript "lid". 
Briefly, the lidar system used here contains a Nd:YAG laser, which emits laser pulses at $20 \mathrm{~Hz}$. The full overlap of the laser beam and the receiver field of view (FOV) for this system is at about $800 \mathrm{~m}$ height. Below this height, an overlap correction can be applied. The experimental determination of the overlap height is described in Wandinger and Ansmann (2002). Measurements of the lidar system were available each $30 \mathrm{~s}$ with a vertical resolution of $7.5 \mathrm{~m}$.

As the signal-to-noise ratio in the channels of the Raman scattered light is too weak during daytime, no independent particle light extinction profiles are available. Therefore, the extinction-to-backscatter ratio, or LR (in sr), an aerosol-typedependent intensive property, was used to convert $\sigma_{\text {bsc }}$ to $\sigma_{\text {ext }}$ by

$\sigma_{\mathrm{ext}}=\mathrm{LR} \times \sigma_{\mathrm{bsc}}$.

Several studies (e.g., Tao et al., 2008; Lu et al., 2011; Ferrare et al., 2001; Müller et al., 2007; Haarig et al., 2016) investigated the LR for different atmospheric conditions and aerosol types, like dust in Groß et al. (2011) and volcanic ash in Ansmann et al. (2010). The studies showed that the LR is a highly variable parameter depending on the predominant aerosol. In this study we used a height-constant LR of $55 \mathrm{sr}$ to derive profiles of $\sigma_{\text {ext }}$ for 355 and 532. These fixed $\mathrm{LR}$ are in agreement with the Raman measurements (direct measurement of LR; Ansmann et al., 1992) during night at the respective period and location. Also the LR fit to longterm observations of different aerosol types at other European continental sides and aerosol types (clean and polluted continental aerosol, mineral desert dust, and smoke, Baars et al., 2016; Groß et al., 2013; Mattis et al., 2004; Müller et al., 2007; Schwarz, 2016).

A height-independent LR of $30 \mathrm{sr}$ for $1064 \mathrm{~nm}$ provided by Omar et al. (2009) was used in this study. This assumption might introduce errors in the retrieval of $\sigma_{\text {ext }}$. Integrat-

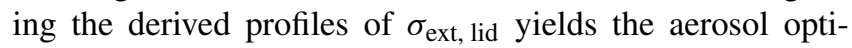
cal thickness (AOD), which was compared with ongoing AERONET (Aerosol Robotic Network; http://aeronet.gsfc. nasa.gov/; station: Melpitz) sun-photometer measurements at wavelengths of 340,500 , and $1020 \mathrm{~nm}$. Both measurements agree well within the uncertainties, which were relatively high due to the very low AOD (e.g., on 14 September: $0.014 \pm 0.001$ for $1020 \mathrm{~nm}, 0.087 \pm 0.004$ for $500 \mathrm{~nm}$ and $0.158 \pm 0.004$ for $340 \mathrm{~nm}$ between 11:50 and 12:20 UTC).

Overall, we consider an uncertainty in the lidar measurements of up to $15 \%$. Wandinger et al. (2016) provide an intercomparison campaign of different EARLINET (European Aerosol Research LIdar NETwork, https://www.earlinet.org/ index.php?id=earlinet_homepage) instruments, including the lidar system used in this work (Polly ${ }^{\mathrm{XT}}$ ). All shown instruments in Wandinger et al. (2016) had a relative deviation of maximum 10 to $20 \%$ to a reference in both extinction and backscattering. Polly ${ }^{\mathrm{XT}}$ (le02 in Wandinger et al., 2016) had maximum deviation of less than $10 \%$. Taking into account the uncertainty increase due to the assumed lidar ratio and the shorter average windows we consider $15 \%$ as a maximum uncertainty as appropriate even though we are well aware that the uncertainty is usually lower.

Besides the validation of the LR for the three wavelengths, we also considered a new method provided by Mamouri and Ansmann (2016) to derive CCN-NC profiles from lidar measurements $\left(N_{\mathrm{CCN}, \text { lid }}\right)$. This method converts particle light extinction coefficients to number concentration of $\mathrm{CCN}$ for different supersaturations and different aerosol types. For continental aerosol (subscript "c"),

$n_{\mathrm{CCN}, \mathrm{SS}, \mathrm{c}}(z)=f_{\mathrm{SS}, \mathrm{c}} \times n_{50, \mathrm{c}, \mathrm{dry}}(z)$,

with

$n_{50, \mathrm{c}, \mathrm{dry}}(z)=c_{60, \mathrm{c}} \times \sigma_{\mathrm{ext}}^{x_{\mathrm{c}}}(z)$,

which has to be applied (Mamouri and Ansmann, 2016) in

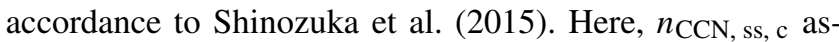
signs the CCN-NC at given supersaturation SS and height $z$ in $\mathrm{cm}^{-3}$. The PNC of particles with a diameter larger than $100 \mathrm{~nm}$ is symbolized by $n_{50, \mathrm{c} \text {, dry }}\left(50 \mathrm{~nm}\right.$ radius). $c_{60}$, c assigns the conversion factor in $\mathrm{cm}^{-3}$ for the ambient aerosol particle light extinction coefficient $\left(\sigma_{\mathrm{ext}}\right)$ in $\mathrm{Mm}^{-1} . x_{\mathrm{c}}$ is the aerosol extinction exponent.

For the cases presented here, Mamouri and Ansmann (2016) provided a value of 1.0 for $f_{\mathrm{ss}, \mathrm{c}}$ for a supersaturation of $0.15 \%$. Therefore, retrieved concentrations of $\mathrm{CCN}$ may underestimate direct measured $\mathrm{CCN}$ concentrations of the mCCNc on ACTOS. Furthermore, for $x_{\mathrm{c}}$ they estimated $0.94 \pm 0.03$ for Germany and a lidar wavelength of $532 \mathrm{~nm}$. They also provided for $c_{60, \mathrm{c}}$ a value of $25.3 \pm 3.3 . n_{50, \mathrm{c} \text {, dry }}$ and consequently $n_{\mathrm{CCN}, \mathrm{ss}, \mathrm{c}}$ can be retrieved with an uncertainty of a factor of 2 (uncertainty of half or double of the retrieved value; Mamouri and Ansmann, 2016).

$\mathrm{CCN}-\mathrm{NC}$ profiles are obtained from particle extinction profiles. These are calculated in this study on the basis of a height-constant LR from the particle backscattering coefficients. This assumption cannot represent any possible layers with different aerosol types, as different aerosols differ in LR. The assumption of a constant LR would underestimate or overestimate the particle extinction coefficient compared to an aerosol with a higher or lower LR and thus also the $\mathrm{CCN}$ number concentration.

\section{Methodology}

In this chapter we will provide an overview of the dataset used in this investigation and the model that is used to determine the aerosol particle optical properties.

\subsection{Case studies}

From the eight ACTOS flights of the intensive measuring period (see Table 2), three were taken due to preferred conditions and thus will be intensively discussed (flights: 


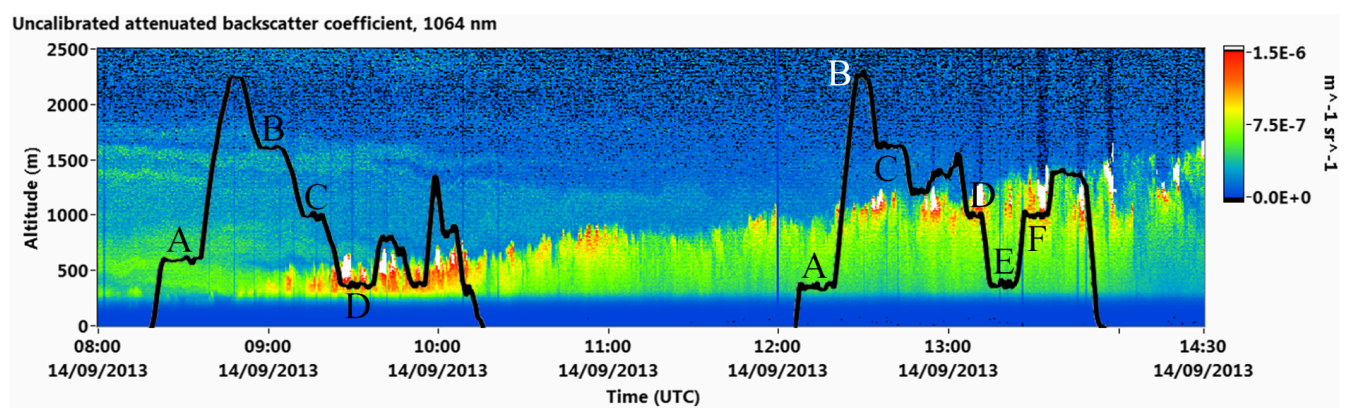

Figure 3. Range-corrected backscatter signal for $1064 \mathrm{~nm}$ derived with Polly $\mathrm{XT}$ on 14 September. The more reddish, the larger is the backscatter signal. The black lines represent the flight patterns of flights $14 \mathrm{a}$ and $\mathrm{b}$. White colors indicate very high backscattering.

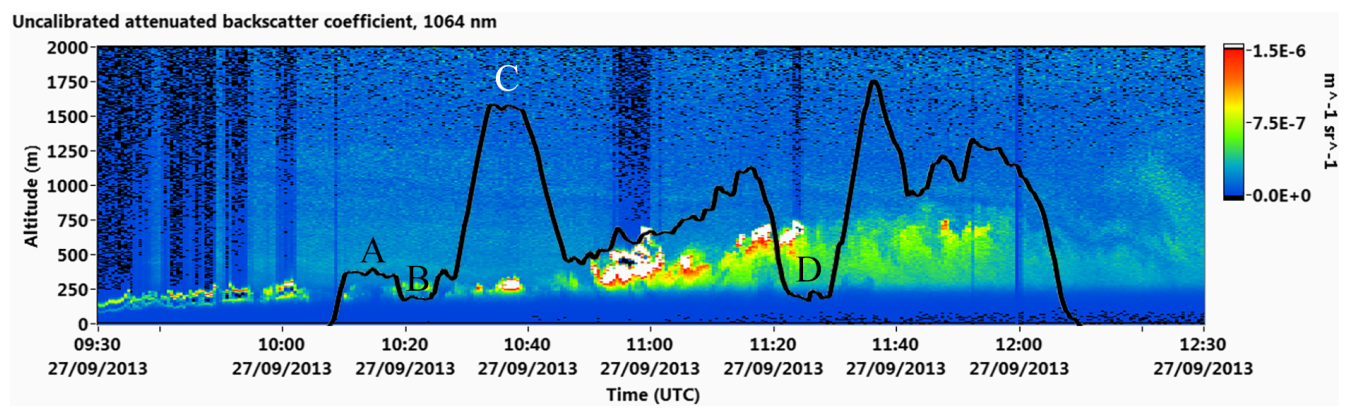

Figure 4. Range-corrected backscatter signal for $1064 \mathrm{~nm}$ derived with Polly ${ }^{\mathrm{XT}}$ on 27 September. The more reddish, the larger is the backscatter signal. The black lines represent the flight patterns of flight $27 \mathrm{a}$. White colors indicate very high backscattering.

20130914a, 20130914b, 20130927a, in the following abbreviated as $14 \mathrm{a}, 14 \mathrm{~b}, 27 \mathrm{a})$. The major preferential condition was clear skies in all altitudes levels in order to prevent the influence of the clouds on AOD measurements of the sun photometer and to ensure that the lidar covers the entire atmospheric column.

Figures 3 and 4 show the time-elevation plot of the rangecorrected attenuated backscatter signal of the lidar system. White areas in the figures represent high backscattering, mostly by clouds. Blue or black areas represent low light backscattering and thus regions of very clean air. Red and yellowish colors indicate enhanced light backscattering by aerosol particles. The overlaying solid black line indicates the height of ACTOS during a measurement flight. Capital letters mark horizontal parts of the flight investigated later in this study.

In particular, during the flights on 14 September 2013, episodes of a cloud-free air column above the lidar were apparent (before leg D on flight 14a, between 10:15 and 12:30 UTC, during leg D on flight $14 \mathrm{~b}$ ). Cloud-free periods did occur during flight 27 a (clouds visible around 10:35, and from 10:50 to 11:30). Furthermore, on 14 September 2013, a residual layer is visible between 08:00 and 10:00 UTC reaching a height of up to $1800 \mathrm{~m}$. Its thickness decreased during daytime and the residual layer vanished at around 12:00 UTC. At the same time, a well-pronounced mixing layer was built up. Its upper boundary is characterized by a sharp gradient of the backscatter signal (Fig. 3). The development of the mixing layer is visible in the lidar measurements from 09:00 UTC and it reached a height of about $1600 \mathrm{~m}$ at 14:00 UTC.

During the measurement flights, Melpitz was dominated by marine air masses influenced by continental pollution. For example, for 14 and 27 September 2013, three $72 \mathrm{~h}$ backward trajectories for the height of 500 (red lines), 1000 (blue lines), and $1500 \mathrm{~m}$ (green lines) aboveground are shown in Figs. 5 and 6 . These trajectories where calculated using the Hybrid Single-Particle Lagrangian Integrated Trajectory (HYSPLIT) model of the Air Resource Laboratory (ARL) of the National Oceanic and Atmospheric Administration (NOAA). HYSPLIT is available at http://www.ready.noaa. gov. A detailed description of the model is available in Stein et al. (2015).

On 14 September 2013, a westerly flow in all heights was apparent. The air masses crossed the North Sea before traveling across the continent to Melpitz. Furthermore, on 27 September 2013, the air masses subsided during the last $36 \mathrm{~h}$ crossing the Baltic Sea. The three air parcels reaching Melpitz in 500, 1000, and $1500 \mathrm{~m}$ originated from Scandinavia and proceeded southwards. In contrast to 14 September 2013, the air parcel with the lowest height in the beginning (green line) in roughly $1500 \mathrm{~m}$ aboveground and reached Melpitz at a higher altitude $(1500 \mathrm{~m})$ than the air par- 
NOAA HYSPLIT MODEL

Backward trajectories ending at 12:00 UTC 14 Sep 13 GFSG meteorological data

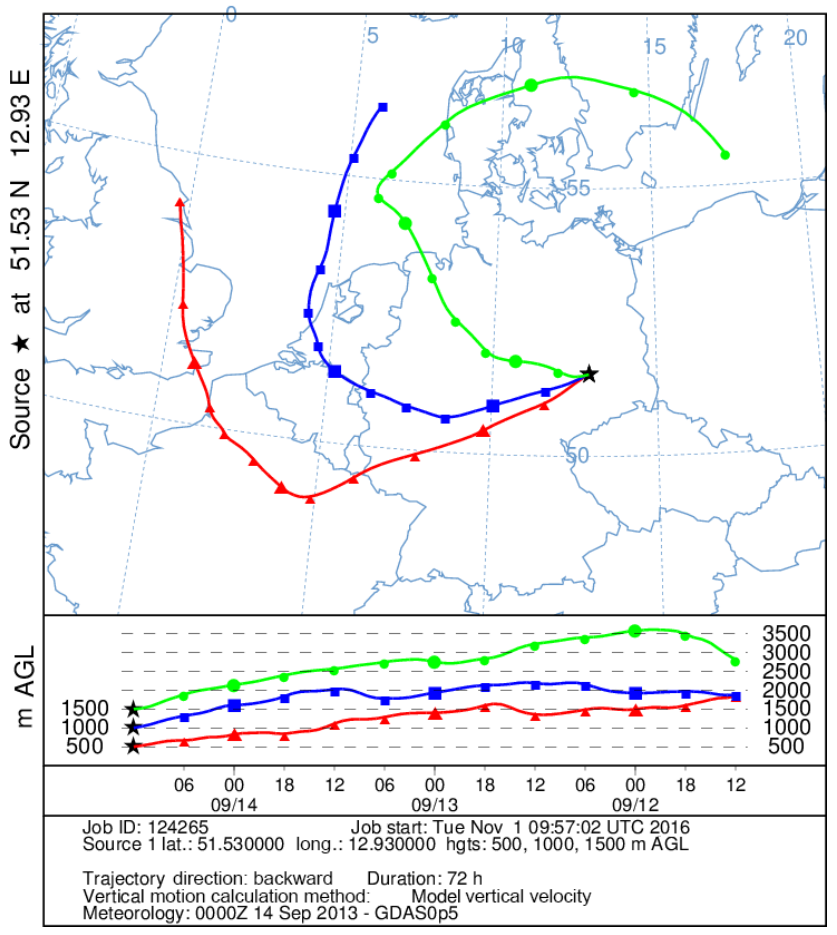

Figure 5. Three $72 \mathrm{~h}$ backward trajectories for 500 (red), 1000 (blue), and $1500 \mathrm{~m}$ (green) aboveground for Melpitz, ending at 14 September, 12:00 UTC.

cel marked by the red and blue, originating from a height of roughly $3000 \mathrm{~m}$.

\subsection{Airborne in situ aerosol optical properties}

In this study, the calculation of aerosol optical properties was performed on the basis of Bohren and Huffman (1983). The complex refractive index, the hygroscopicity, and the mixing of the aerosol particles are needed to compare calculated optical properties with measured ones. A scheme of our method is shown in Fig. 7. The method and its application are described in the following.

The mixing state can be assumed by different mixing approaches. The dry-state optical closure study by $\mathrm{Ma}$ et al. (2014) shows that the approach of internally mixed coated (aerosol particles consists of a core surrounded by a shell; core-shell approach) aerosol particles results in the best agreement between modeled and measured hemispheric backscatter coefficients for Melpitz. Furthermore, Zhang and Thompson (2014) and Kahnert et al. (2012) discussed the mixing morphology and its influence on particle light absorption and scattering. Zhang and Thompson found that the core-shell mixing assumption leads to higher modeled particle absorption than the approach of internally homogeneous mixed particles ( $24 \%$ difference, $115 \%$ in maximum), espe-
NOAA HYSPLIT MODEL

Backward trajectories ending at 12:00 UTC 27 Sep 13 GFSG meteorological data

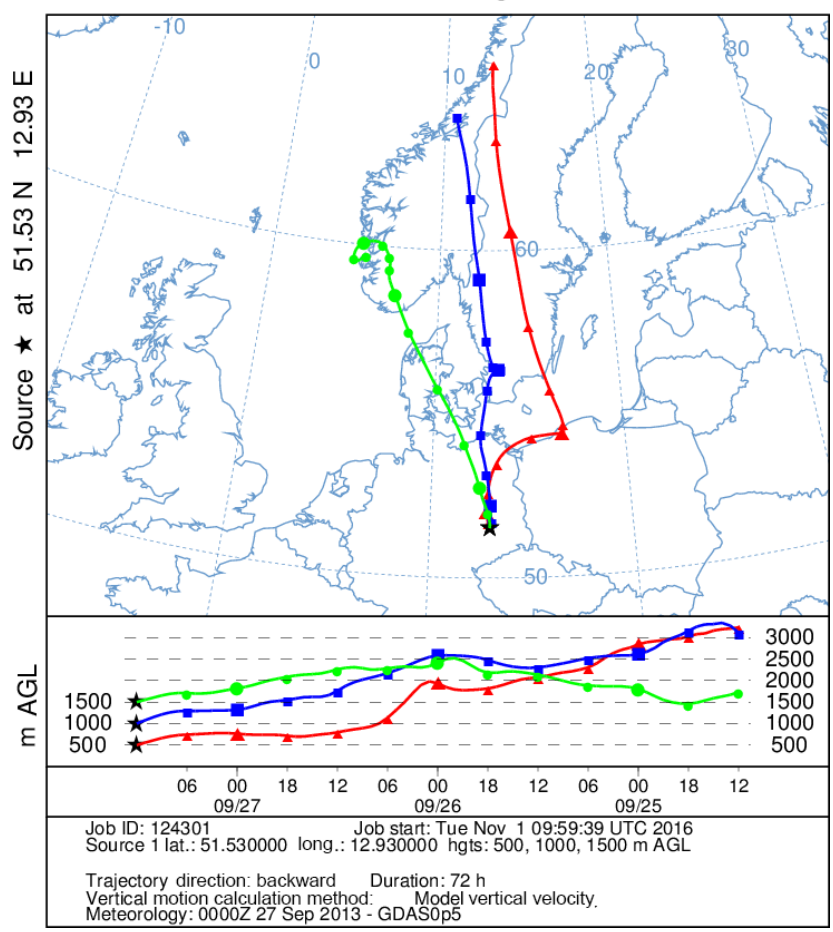

Figure 6. Three $72 \mathrm{~h}$ backward trajectories for 500 (red), 1000 (blue), and $1500 \mathrm{~m}$ (green) aboveground for Melpitz, ending at 27 September, 12:00 UTC.

cially when the core of light-absorbing carbon is small compared to the shell. In contrast, for particle light scattering they did not observe a significant difference between both approaches. Kahnert et al. (2012) showed that the core-shell model underestimates the particle light absorption but reproduces the particle light extinction sufficient. In conclusion, the mixing approach used in this study is applicable for modeling aerosol particle light extinction.

This discussion in the previous paragraph implies, although the particle light absorption is overestimated, that the core-shell mixing assumption is satisfying for the aerosol apparent in Melpitz. That means that in this work it is assumed that the aerosol particles consist of a core of water-insoluble highly absorbing soot (eBC) and a shell of non-refractory less-absorbing material, which includes organic matter, ammonia nitrate, and sulfate species.

The Mie code (based on Mie theory; Mie, 1908) calculates the scatter, extinction, absorption, and backscatter efficiency of a single, spherically symmetric aerosol particle with a given complex refractive index of its shell and core and a given diameter of the core and thickness of the shell.

The goal of this study is to investigate the aerosol particle light extinction $\left(\sigma_{\text {ext }}\right)$ and backscatter coefficient $\left(\sigma_{\text {bsc }}\right)$ in ambient state. $\sigma_{\mathrm{bsc}}$ can be calculated with Eq. (6) and 


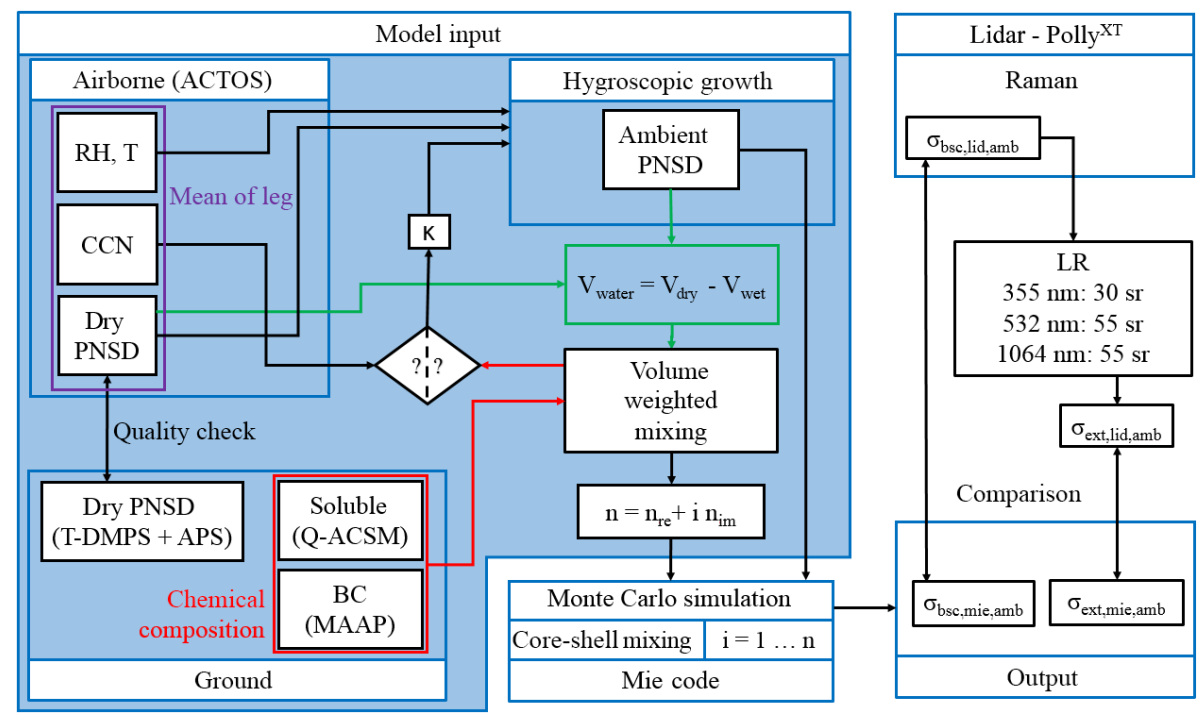

Figure 7. Flowchart of the algorithm to convert airborne in situ measurements to aerosol particle optical properties in ambient state.

$\sigma_{\text {ext }}$ with Eq. (7) (adapted and modified from Virkkula et al., 2011):

$\sigma_{\mathrm{bsc}}(\lambda)=\frac{1}{4 \pi} \int Q_{\mathrm{bsc}}\left(\lambda, D_{\mathrm{p}}, n\right) \frac{\pi D_{\mathrm{p}}^{2}}{4} \frac{\mathrm{d} N\left(D_{\mathrm{p}}\right)}{\mathrm{d} \log D_{\mathrm{p}}} \mathrm{d} D_{\mathrm{p}}$,

$\sigma_{\text {ext }}(\lambda)=\int Q_{\text {ext }}\left(\lambda, D_{\mathrm{p}}, n\right) \frac{\pi D_{\mathrm{p}}^{2}}{4} \frac{\mathrm{d} N\left(D_{\mathrm{p}}\right)}{\mathrm{d} \log D_{\mathrm{p}}} \mathrm{d} D_{\mathrm{p}}$

Hereby $Q_{\mathrm{bsc}}\left(\lambda, D_{\mathrm{p}}, n\right)$ and $Q_{\mathrm{ext}}\left(\lambda, D_{\mathrm{p}}, n\right)$ are the backscatter and extinction efficiency, respectively, of aerosol particles with a diameter $D_{\mathrm{p}}$ and a complex refractive index $n$ at a wavelength $\lambda$ (Virkkula et al., 2011). The equation to derive the particle light scattering efficiency for coated particles is provided by Bohren and Huffman (1983) and Dombrovsky (2011). [d $\left.N\left(D_{\mathrm{p}}\right)\right] /\left[\mathrm{d} \log D_{\mathrm{p}}\right]$ denotes the PNSD of the aerosol and can be measured by particle size spectrometers (see Sect. 2.2 and 2.3.2).

Aerosol particles in humid ambient conditions are underlying a growth due to water vapor uptake. The magnitude of growth depends on particle size, hygroscopicity parameter $\kappa$, and ambient RH. Hygroscopic growth changes size, shape, and the complex refractive index of aerosol particles. The change of shape is not considered in this study because the particles are assumed to be spherical in dry state anyway.

Measurements of the aerosol particle chemical composition (see Sect. 2.2.2) provided volume fractions of aerosol particle compounds such as organic and black carbon, ammonium nitrate, and ammonium sulfate. A volume-weighted sum of $\kappa$ of the aerosol particle compounds provided a mean $\kappa$ of the entire aerosol particle. Measurements of cloud condensation nuclei may also provide $\kappa$ as described in Henning et al. (2014) and Sect. 2.2.3 (see Fig. 7, rhombus with question marks).
Table 3. Real $\left(n_{\text {re }}\right)$ and imaginary part $\left(n_{\text {im }}\right)$ of the complex refractive index $(n)$ of the aerosol components used for the volumeweighted mixing in the algorithm to derive $n$ of the core and the shell of the aerosol particles. Also the SD $(\sigma)$ of each part of $n$ is given in which the algorithm varies the $n$ of each compound to provide a possible range of values for $\sigma_{\text {ext }}$ and $\sigma_{\mathrm{bsc}}$. The values in this table where taken out of Ma et al. (2014).

\begin{tabular}{lrrrr}
\hline Component & $n_{\text {re }}$ & $\sigma\left(n_{\text {re }}\right)$ & $n_{\text {im }}$ & $\sigma\left(n_{\text {im }}\right)$ \\
\hline Soluble & 1.53 & $0.5 \%$ & $1 \times 10^{-6}$ & - \\
eBC & 1.75 & $4 \%$ & 0.55 & $6.6 \%$ \\
Water & 1.33 & $0.5 \%$ & 0 & - \\
\hline
\end{tabular}

Here, we assumed that in the dry state each aerosol particle consists of the same constant volume fraction of each component, because no size-resolved particle chemical composition measurements with a high time resolution were available. Petters and Kreidenweis (2007) provided a semi-empirical parameterization for the diameter of a particle with a given hygroscopicity in ambient conditions as a function of RH and $T$. Using this parameterization allows us to derive the PNSD in ambient state.

The difference in the volume of the aerosol particles in ambient and dry state is the total volume of the water $V_{\text {wat }}=$ $V_{\text {aer, ambient }}-V_{\text {aer, dry }}$ accumulated on the aerosol particles (green rectangle in the scheme). A detailed description of the Köhler theory is given in Köhler (1936).

The complex refractive index of the particle core $(\mathrm{eBC})$ is known. In dry state, the shell consists of different nonrefractory compounds (subscript "s"), which are assumed to have the same complex refractive index (see Table 3). In ambient state the aerosol particle shell is made up of the nonrefractory material and the water (subscript "w") itself. The 
algorithm used here applied a volume-weighted sum to derive the complex refractive index $n=n_{\mathrm{re}}-i n_{\mathrm{im}}$ of the aerosol particle shell in the ambient state:

$$
\begin{aligned}
n_{\text {shell, amb }} & =f_{\mathrm{v}, \mathrm{s}}\left(n_{\mathrm{re}, \mathrm{s}}+i n_{\mathrm{im}, \mathrm{s}}\right) \\
& +f_{\mathrm{v}, \mathrm{w}}\left(n_{\mathrm{re}, \mathrm{w}}+i n_{\mathrm{im}, \mathrm{w}}\right),
\end{aligned}
$$

where $f_{\mathrm{v}, \mathrm{s}}$ is the volume fraction of the non-refractory compounds in the shell and $f_{\mathrm{v}, \mathrm{w}}$ the volume fraction of the water. $n_{\mathrm{re}, \mathrm{s}}, n_{\mathrm{re}, \mathrm{w}}$ are the real part of the complex refractive index of the non-refractory material and the water, respectively, and $n_{\mathrm{im}, \mathrm{s}}$ and $n_{\mathrm{im}, \mathrm{s}}$ denote the imaginary part of the refractive index of the soluble material and the water, respectively. The complex refractive index of water and the non-refractory material is shown in Table 3.

Furthermore, the diameter of the light-absorbing eBC core for each aerosol particle has to be taken into account for the calculation of the aerosol optical properties. With the volume fraction of the eBC $\left(f_{\mathrm{v}, \mathrm{eBC}}\right)$ derived from the chemical composition measurements (see Sect. 2.2.2), the diameter of the eBC core $\left(D_{\mathrm{eBC}}\right)$ of each aerosol particle with a diameter of $D_{\mathrm{p}}$ can be calculated according to Ma et al. (2014):

$$
D_{\mathrm{eBC}}\left(D_{\mathrm{p}}, f_{\mathrm{v}, \mathrm{eBC}}\right)=D_{\mathrm{p}} f_{\mathrm{v}, \mathrm{eBC}}^{1 / 3} .
$$

A Monte Carlo simulation, also used in Ma et al. (2014), is implemented in the here provided method to cover a possible range of results of $\sigma_{\mathrm{ext}}$ and $\sigma_{\mathrm{bsc}}$ introduced by measurement uncertainties in the input parameters and due to their spatiotemporal variability. A calculation of $\sigma_{\mathrm{ext}}$ and $\sigma_{\mathrm{bsc}}$ grounds on a PNSD of the aerosol. The Monte Carlo simulation repeats the calculation of $\sigma_{\text {ext }}$ and $\sigma_{\mathrm{bsc}} 50$ times, varying the input parameters within the respective uncertainties and SDs of mean uniformly distributed.

For the considered period (e.g., length of a horizontal leg) the mean and the respective standard deviation (SD) was calculated from the measurements of the PNSD and the prevalent ambient RH and $T$. The aerosol hygroscopicity was derived by averaging the volume fractions of each considered species on the basis of the Q-ACSM and MAAP measurements determined between 08:00 and 15:30 UTC, which cover the range of the flight times. The complex refractive index of the aerosol particles was calculated according to the mixing rule introduced by Eq. (10), where each complex refractive index of the considered aerosol component (water, water soluble and insoluble) was varied within its uncertainties given in Table 3. By calculating the average of the output of the 50 simulations the algorithm provides the average optical properties for the aerosol particles in their ambient state as well as the uncertainty range due to the variability of the input parameters. A larger number of simulations does not change the SD of the output.

In the following, the aerosol optical properties calculated with this algorithm on the basis of in situ measurements are assigned with the subscript "mie".

\section{Results}

In this section ground-based measurements will be related to vertical profiles to investigate the representativeness of in situ measurements on the ground for the PBL. Furthermore, the results of the in situ based calculations and measurements from the lidar will be shown and compared.

\subsection{Representativeness of ground in situ measurements for the PBL}

In this section we compare the PNSD, the aerosol PNC and the $\mathrm{CCN}-\mathrm{NC}$ measured on the ground and aboveground with ACTOS.

\subsubsection{Particle number size distribution}

The scans of PNSD in legs A, D, E, and F of flight $14 \mathrm{~b}$ were performed within the mixing layer (see Fig. 3), while the scans of legs $\mathrm{B}$ and $\mathrm{C}$ were done above the mixing layer. A comparison of PNSDs measured during legs $\mathrm{C}$ and $\mathrm{B}$ with ground-based measurements is thus not useful. We focus therefore on the PNSD of legs A, D, E, and F.

The averaged PNSDs at standard conditions of legs A, D, E, and $\mathrm{F}$ are shown in Fig. 8 (solid lines). The corresponding PNSD measured at Melpitz observatory is shown as dashed line with the respective color in each figure. Since there was no scan of ground-based PNSD available during legs D and $\mathrm{E}$, the average of the PNSD one scan before and after the respective leg was taken for these legs. For the selected case, the ground-based PNSD agrees with the PNSD of legs A, $\mathrm{E}$, and $\mathrm{F}$ in the size range of 30 to $100 \mathrm{~nm}$ within $10 \%$. For aerosol particles smaller than $30 \mathrm{~nm}$, the difference between the curves increases, but the shape of both number size distributions is similar. In the size range of the accumulation mode $(100$ to $500 \mathrm{~nm}$ ) the mean airborne PNSD of legs E and $\mathrm{F}$ was up to 2 times larger than the PNSD observed on the ground at the same time. This clearly corresponds with the integrated aerosol PNC recorded with the OPSS ( $N_{\text {OPSS }}$ ) on ACTOS (see Fig. 9), where the total PNC derived with the CPC $\left(N_{\mathrm{CPC}}\right)$ increases with height. During the first profile of flight $14 \mathrm{~b} N_{\mathrm{OPSS}}$ increases with increasing height up to $\sim 650 \mathrm{~m}\left(18\right.$ to $\left.\sim 45 \mathrm{~cm}^{-3}\right)$. The measurements in leg $\mathrm{D}$ were performed at the top of the planetary boundary layer and therefore probably may have been influenced by mixing processes of clean air of the free troposphere and the more polluted air within the PBL. This explains the different shape and concentration of the PNSD of leg D in comparison to the ground-based measurements.

Differences in the airborne and ground-based PNSD may also occur due to horizontal inhomogeneity. For example, Fig. 9 shows the mean $N_{\text {OPSS }}$ measured within a layer between 950 and $1050 \mathrm{~m}$ height between 13:06 and 13:34 UTC on 14 September (measurements during legs $\mathrm{D}$ and $\mathrm{F}$ ). The 


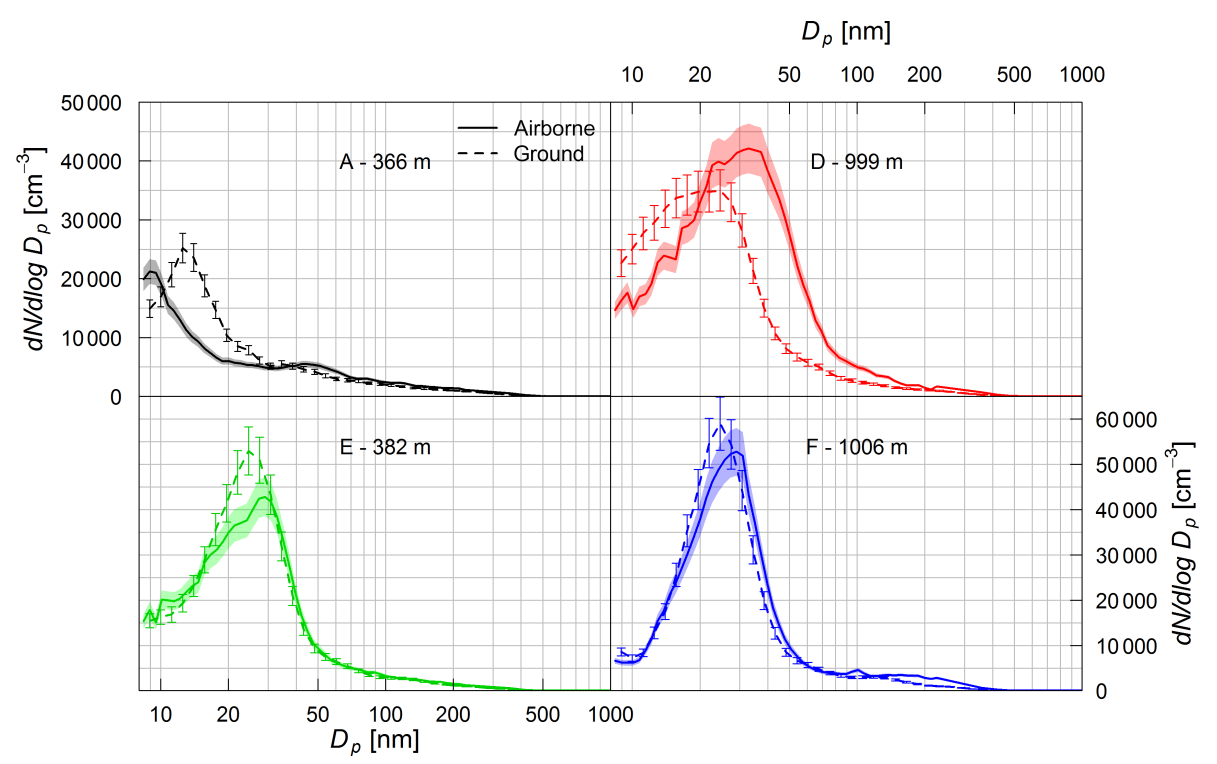

Figure 8. Airborne (solid lines) mean PNSD of flight 14b at standard conditions recorded during legs A (black), D (red), E (green), and F (blue) with the corresponding PNSD measured at Melpitz (dashed lines). Error bars and shaded areas represent the TROPOS standard uncertainty of TROPOS-built MPSS systems of $10 \%$.

red triangle symbolize the measurement site in Melpitz. The more reddish the color is, the larger the PNC.

During legs D and F of flight 14b, the horizontal distance between ACTOS and Melpitz was between 500 and $4700 \mathrm{~m}$. Within this distance the aerosol PNC, PNSD, and chemical composition may differ in the observed altitude. During the leg from south to north, the PNC varied by a factor of 2 , probably due to local influences on the transported pollution. This example demonstrates the horizontal variation of number concentration and potential deviation between groundbased and vertical measurements due to the horizontal distance.

In conclusion, for aerosol particles larger than $30 \mathrm{~nm}$ we can state for the case presented here that ground-based measurements of the PNSD are representative of higher atmospheric layers within the PBL. For smaller particles, local events alter the PNSD and cannot be detected by groundbased measurements. The agreement is best for measurements of the PNSD in the lowest available altitude. Groundbased measurements are not representative of the observations near the top of the PBL. Here, entrainment and mixing processes affect the aerosol.

\subsubsection{Aerosol particle total number and cloud condensation nuclei concentration}

Figure 10a and $\mathrm{b}$ each show two different profiles (black and blue) of the PNC measured with the CPC on ACTOS ( $N_{\mathrm{CPC}}$, left in each panel) and the $\mathrm{CCN}-\mathrm{NC}\left(N_{\mathrm{CCN}}\right.$, right in each panel) recorded with the mCCNc on ACTOS for flights 14b (panel a) and 27a (panel b). Additionally, the integrated PNC (left of each panel) of the PNSD and the CCN-NC (right of each panel) measured at the Melpitz observatory are shown (red crosses). Furthermore, CCN-NC profiles are shown derived on the basis of the approach of Mamouri and Ansmann (2016) (solid lines in left panels, shaded area marks the uncertainty). The first profile of flight $14 \mathrm{a}$ (black) was measured between 12:05 and 12:27 UTC. The second (blue) was measured between 13:47 and 13:54 UTC. The respective measurements of the integrated PNC were sampled at $11: 30,11: 50$, and 12:10 UTC. For the second profile, the respective PNC at Melpitz observatory was measured at 13:10, 13:50, and 14:10 UTC and the CCN-NC at 10:33, 12:43, and 14:53 UTC. The first profile of flight 27 a (black) was taken at the beginning of the measurement flight (between 10:24 and 10:34 UTC) whereas the second profile (blue) was conducted in the fully developed mixing layer between 11:29 and 11:36 UTC (see Fig. 4; ascending part after leg D of the flight 27a).

The first profile of flight 14a (Fig. 10a, black) shows an inversion at $1150 \mathrm{~m}$ altitude where $N_{\mathrm{CPC}}$ decreased from 13000 to around $1000 \mathrm{~cm}^{-3}$ (top of PBL). The layer below $350 \mathrm{~m}$ altitude (part of the flight from Beilrode to Melpitz) shows a 2 times smaller concentration than the layer above. Since the first part of the profile was performed on the way to Melpitz, a horizontal variability of the aerosol might be the reason for this behavior. The two distinct peaks (up to $12000 \mathrm{~cm}^{-3}$ ) in the lower part of the $N_{\text {CPC }}$ profile are probably caused by exhaust gases of the helicopter because an increased $\mathrm{CO}_{2}$ concentration was measured at the same time. Above the lower part, the atmosphere is well mixed between 350 and $1150 \mathrm{~m}$ altitude with a stable $N_{\mathrm{CPC}}$ in the range from 10000 to $12000 \mathrm{~cm}^{-3}$ and slightly larger PNC below the 


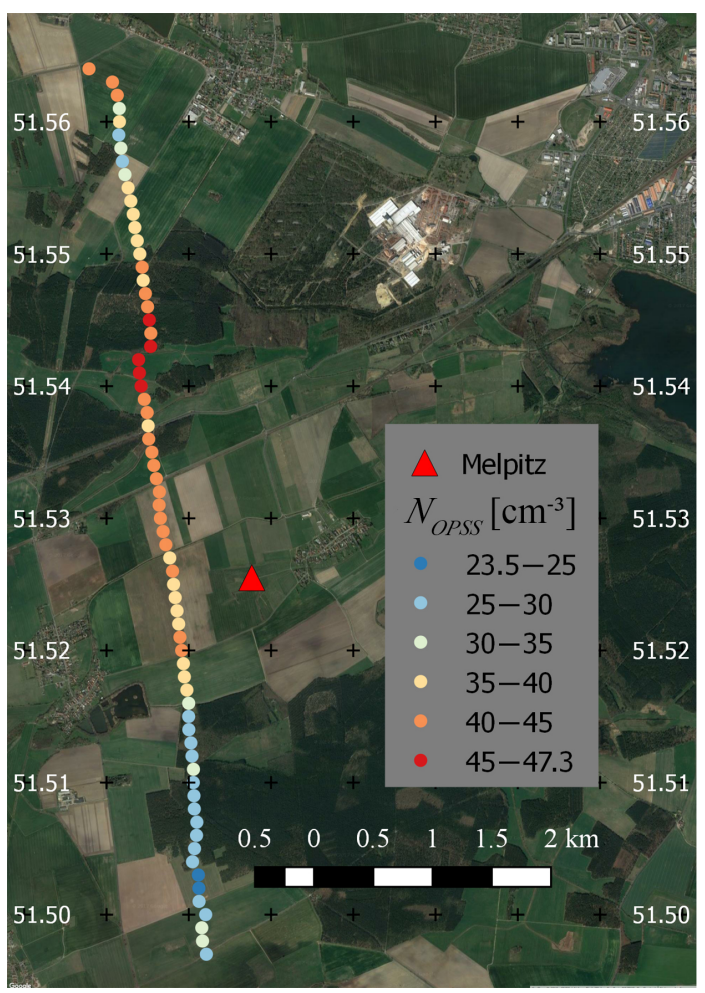

Figure 9. Horizontal distribution of the mean PNC $\left(N_{\text {OPSS }}\right)$ for particles with an optical diameter of $356 \mathrm{~nm}$ to $2.8 \mu \mathrm{m}$ within layer of 950 to $1050 \mathrm{~m}$ aboveground recorded between 13:06 and 13:34 UTC on 14 September (legs D and F of flight 14b). The more reddish the symbol the higher is the concentration. The red triangle represents the measurement site in Melpitz.

inversion. The $N_{\mathrm{CPC}}$ recorded during the second profile of flight $14 \mathrm{~b}$ (blue) increases slightly with height. The second profile of flight $14 \mathrm{~b}$ was completely located within the PBL since no sharp decrease of $N_{\mathrm{CPC}}$ with height was observed.

Aerosol measurements at the observatory in Melpitz showed an event of high PNC between 12:00 and 14:00 UTC. The elevated PNC is probably caused by a transported plume since the $\mathrm{SO}_{2}$ concentration increased by a factor of 10 at the same time (see Fig. 11). This advected plume was obviously not lifted into higher atmospheric layers. Thus, the groundbased measurements are decoupled from those in higher altitudes and are therefore not representative of the PBL in this case.

In contrast to the ground-based measurements in Melpitz and excluding the case when the exhaust gases influenced the airborne measurements, the measurements of the CPC at the surface in Beilrode were representative of the atmospheric layers above, since the PNC is as high as in higher atmospheric layers.

Airborne measurements of $N_{\mathrm{CCN}}$ during the first profile of flight $14 \mathrm{~b}$ (black dots) started above the top of the mixing layer and are therefore not of further interest. In the second profile (blue dots) $N_{\mathrm{CCN}, \mathrm{mCCNc}}$ varies between 886 and
$2474 \mathrm{~cm}^{-3}$ with an average of $1456 \pm 301 \mathrm{~cm}^{-3}$. The second profile was taken between two ground-based measurements (12:43 and 14:53 UTC). At both times the ground-based measurements in Melpitz resulted in smaller CCN-NC (600 and $976 \mathrm{~cm}^{-3}$ ) than in higher altitudes. In contrast, the lowermost measurements of the $\mathrm{mCCNc}\left(1279 \pm 91 \mathrm{~cm}^{-3}\right.$ within 100 and $130 \mathrm{~m}$ altitude) on ACTOS (considered as measurement on the ground) in Beilrode do represent the measurements during the last profile of flight $14 \mathrm{~b}$. Spatial variability may explains that the ground-based $\mathrm{CCN}-\mathrm{NC}$ measurements in Melpitz are not representative of collocated vertical profiles. In contrast, the lowermost CCN-NC measurements $\left(\sim 700 \mathrm{~cm}^{-3}\right)$ derived with the mCCNc on ACTOS are representative of the higher atmospheric layers.

In the first profile of flight $27 \mathrm{a}$ (black) the top of the mixing layer is around $250 \mathrm{~m}$ altitude marked by a sharp decrease in both $N_{\mathrm{CPC}}$ and $N_{\mathrm{CCN}, \mathrm{mCCN}}$. In the second profile (blue) three distinct layers are apparent. Up to a height of around $600 \mathrm{~m} N_{\mathrm{CPC}}$ and $N_{\mathrm{CCN}, \mathrm{mCCNc}}$ are almost constant at around 2000 and $600 \mathrm{~cm}^{-3}$, respectively. Between 600 and $1050 \mathrm{~m}$ altitude an atmospheric layer was apparent with aerosol highly variable in $N_{\mathrm{CCN}, \mathrm{mCCN}}$ and $N_{\mathrm{CPC}}$. Compared to the layer below $N_{\mathrm{CPC}}$ is up to 6 times and $N_{\mathrm{CCN}, \mathrm{mCCNc}}$ up to 2 times larger. Above that $N_{\mathrm{CPC}}$ is constant at around $1000 \mathrm{~cm}^{-3}$ with a sharp increase in the highest $50 \mathrm{~m}$ of the profile. Note that $N_{\mathrm{CPC}}$ in the highest layers shows the same values as in the first profile in this height. In the layer above $1050 \mathrm{~m} N_{\mathrm{CCN}, \mathrm{mCCNc}}$ shows a slight decrease from around 500 to $100 \mathrm{~cm}^{-3}$.

For both profiles, the ground-based measurements (Melpitz) of both the PNC and the CCN-NC agree with the airborne measurements within the mixing layer (except in the second profile for heights between $\sim 500$ and $\sim 1000 \mathrm{~m}$ ). During the first profile the mixing layer height was very low $(250 \mathrm{~m})$ and therefore only a small part of the profile was situated within the mixing layer. However, extrapolating the measured values of $N_{\mathrm{CPC}}$ and $N_{\mathrm{CCN}, \mathrm{mCCNc}}$ in the lowest available altitude to the ground leads to a good agreement with the respective ground-based measurements at Melpitz at 09:50 and 10:30 UTC for the PNC and 10:20 UTC for CCN$\mathrm{NC}$, respectively.

In the second profile of $N_{\mathrm{CPC}}$ and $N_{\mathrm{CCN}, \mathrm{mCCN}}$ (each blue) two distinct layers in a height of around $600 \mathrm{~m}$ and between 800 and $1100 \mathrm{~m}$ altitude were observed. These layers are characterized by an up to 6 times higher PNC and up to 2 times higher CCN-NC than below. The lower layer is located within the PBL at its top, whereas the upper layer is located within the residual layer above the PBL. The higher PNC was caused by a new particle formation event within the residual layer, which also was observed by Wehner et al. (2010). These new particle formation events can also lead to higher PNC via mixing and entrainment processes at the top of the PBL, which was present at around $600 \mathrm{~m}$ altitude (see Fig. 10b left panel sharp decrease in $N_{\mathrm{CCN}, \mathrm{mCCN}}$ derived with the lidar). Below, within the well mixed PBL, the in 

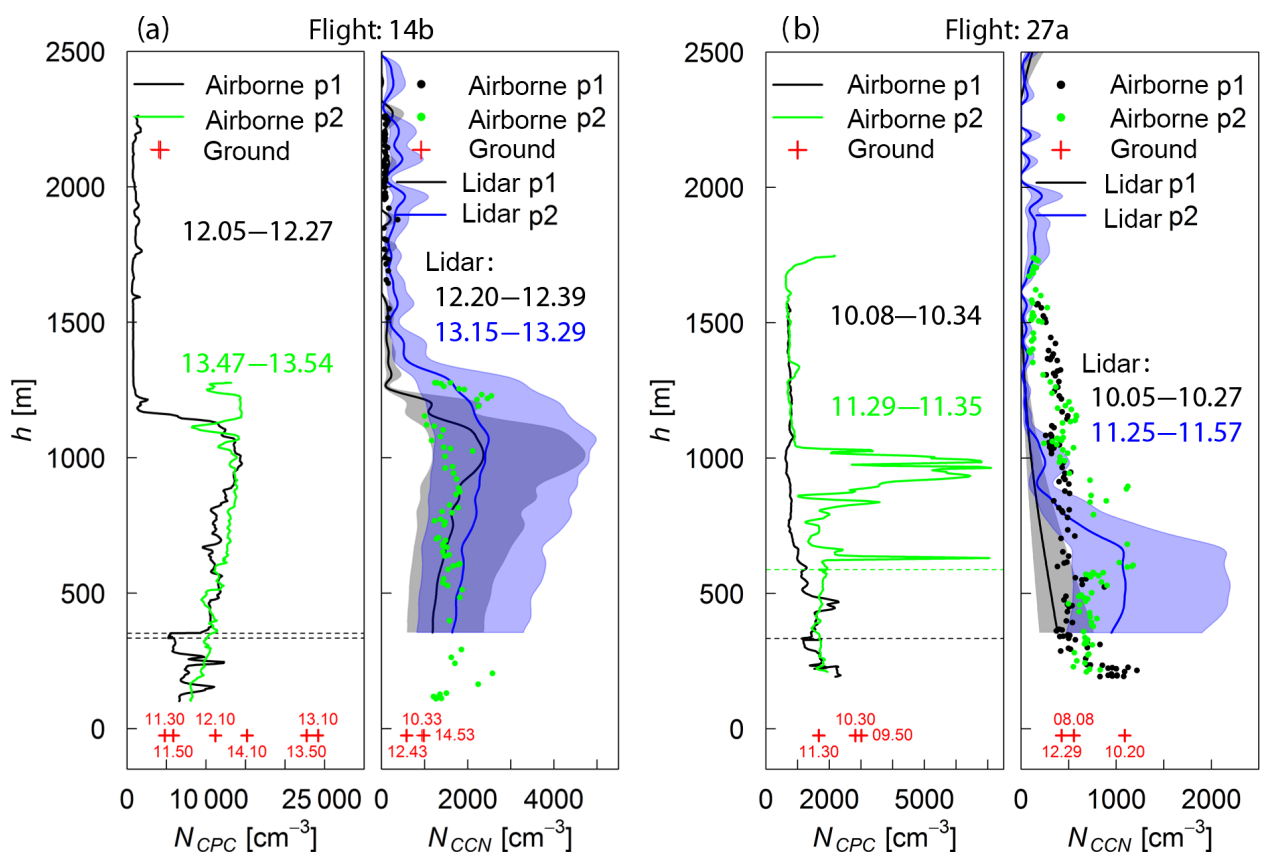

Figure 10. The figure shows profiles of the PNC (solid line; shown on the left side of each panel) and CCN-NC (shown on the right) conducted during flights $14 \mathrm{~b}$ (a) and 27a (b). The airborne in situ measurements of the CCN are shown as dots and lidar-based measurements as a solid line with shaded area. Furthermore the ground-based measurements (red crosses, measured at the same time) of the respective parameters. Two airborne profiles p1 (black) and p2 (green) are shown for each flight. The shaded area around the lidar-based CCN-NC profiles symbolizes the uncertainty of factor of 2. Profiles p1 (black) and p2 (green) of flight 14b were recorded between 12:05 and 12:27 and between 13:47 and 13:54 UTC, respectively. The corresponding lidar-based profiles (lidar p1; black, and lidar p2; blue) were determined in the period 12:20-12:39 and 13:15-13:29 UTC, respectively. Profiles p1 (black) and p2 (green) of flight 27a were recorded at 10:08-10:34 and 11:29-11:35 UTC, respectively. The corresponding lidar-based profiles were determined in the period 10:05-10:27 and 11:25-11:57 UTC, respectively. The horizontal black and blue dashed lines represent the height in which different vertical sections of the flight have been combined to the respective shown profiles.

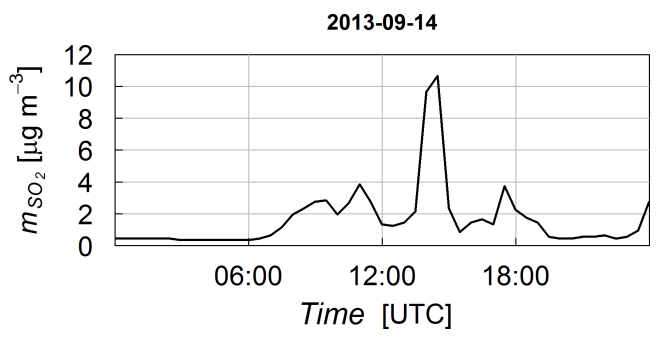

Figure 11. $\mathrm{SO}_{2}$ mass concentration measured at Melpitz observatory on 14 September 2013.

situ airborne measurements show stable values of the PNC $\left(N_{\mathrm{CPC}}\right.$ of around $\left.1800 \mathrm{~cm}^{-3}\right)$ and the CCN-NC $\left(N_{\mathrm{CCN}, \mathrm{mCCNc}}\right.$ of around $700 \mathrm{~cm}^{-3}$ ). We furthermore assume that the larger $\mathrm{CCN}-\mathrm{NC}$ were caused by mixing processes with the residual layer at the top of the PBL. An increase in the ground-based CCN-NC was not observed.

We conclude that ground-based measurements can be representative of the PBL, especially in its well-mixed state. However, local events, like new particle formation events in the residual layer or at the top of the PBL, and pollu- tion plumes near the ground have to be considered. Note that ground-based measurements can represent the PBL in vertical column above only, because spatial variability was observed for the parameters presented here and therefore collocation also has to be considered.

\subsection{Intercomparison of in situ and lidar-based CCN-NC}

Figure 10 shows in the left parts of both panels the CCN-NC derived with the mCCNc on ACTOS (green and black dots) and derived with the approach of Mamouri and Ansmann (2016) (black and blue solid lines with shaded area). Within the given uncertainties of the lidar-based approach (factor of 2, shaded area), the in situ measurements agree with the lidar-based approach, especially within the planetary boundary layer, since the uncertainty range (shaded area) covers almost all mCCNc data points. Above the PBL the agreement is less distinct, especially in the case of flight 27 a for both profiles. In this case we assume that a different aerosol type is prevalent so that the approach of Mamouri and Ansmann (2016) for continental aerosol is not entirely applicable for the investigated altitudes. 
Table 4. Overview of start and end time of the profiles conducted during the flights $14 \mathrm{a}, 14 \mathrm{~b}$, and $27 \mathrm{a}$. Also the averaging period for the respective lidar profiles is given.

\begin{tabular}{lccc|cc}
\hline & \multicolumn{2}{c}{ ACTOS } & \multicolumn{2}{c}{ Lidar } \\
\hline Flight & Profile & $\begin{array}{c}\text { Start } \\
{[\text { UTC] }}\end{array}$ & $\begin{array}{c}\text { End } \\
{[\text { UTC] }}\end{array}$ & $\begin{array}{c}\text { Start } \\
\text { [UTC] }\end{array}$ & $\begin{array}{c}\text { End } \\
{[U T C]}\end{array}$ \\
\hline $14 \mathrm{a}$ & 1 & $08: 50$ & $09: 26$ & $08: 50$ & $09: 24$ \\
$14 \mathrm{~b}$ & 1 & $12: 05$ & $12: 27$ & $12: 20$ & $12: 39$ \\
$14 \mathrm{~b}$ & 2 & $13: 47$ & $13: 54$ & $13: 15$ & $13: 29$ \\
$27 \mathrm{a}$ & 1 & $10: 08$ & $10: 34$ & $10: 05$ & $10: 27$ \\
$27 \mathrm{a}$ & 2 & $11: 29$ & $11: 35$ & $11: 25$ & $11: 57$ \\
\hline
\end{tabular}

Figure 12 shows the correlation of the airborne-based and lidar-based CCN-NC. All data points were derived for five profiles conducted during the three flights (14a (one profile), $14 \mathrm{~b}$ (two profiles), and 27a (two profiles)) and were logarithmized to prevent an overrepresentation of data clusters. The data points were correlated for altitudes above $350 \mathrm{~m}$. For each $\mathrm{mCCNc}$ measurement, the respective CCN-NC (same altitude as ACTOS at this moment) from the corresponding smoothed lidar profile (see Fig. 10 and Table 4) and the associated altitude was taken. Table 4 shows the start and end time of the airborne profiles as well as the averaging period of the respective lidar profiles. The given error bars assign the given uncertainty of the lidar approach of factor of 2 and the assumed uncertainty of $10 \%$ for the $\mathrm{mCCNc}$ measurements.

On average the CCN-NC derived from the lidar fit to the airborne CCN-NC measurements (fit with slope 0.994) with a high correlation coefficient of 0.977 . This shows that this approach is a feasible instrument to evaluate $\mathrm{CCN}-\mathrm{NC}$ profiles with remote sensing. Additionally, in Fig. 12 it is clearly visible that the lidar approach overestimates the airborne CCN-NC measurements for values of $\log _{10}\left(N_{\mathrm{CCN}, \mathrm{mCCNc}}\right)$ from 2.7 to $3.4\left(500\right.$ to $2500 \mathrm{~cm}^{-3}$ in real conditions) by a factor of 2 , whereas in the range from $\log _{10}\left(N_{\mathrm{CCN}, \mathrm{mCCNc}}\right)=1.8$ to $2.5\left(60\right.$ to $\sim 320 \mathrm{~cm}^{-3}$ real concentrations) the lidar approach underestimates. This may indicate different aerosol types and might explain the low correlation in these regimes. Note that in the regime up to $\log _{10}\left(N_{\mathrm{CCN}, \mathrm{mCCNc}}\right)=1.8$ the lidar approach overestimates the mCCNc measurements up to a factor of 5 . In this case we assume that the aerosol loading is too low for a reliable retrieval of CCN-NC.

We used Eqs. (6) and (7) to derive the CCN-NC from the lidar measurements. These equations were derived for continental aerosol. However, the characterization of the aerosol is important since an aerosol layer above the PBL might have different microphysical and chemical properties. Furthermore, the horizontal inhomogeneities are not entirely captured by the lidar but can be resolved by ACTOS. The shortest duration of one ACTOS profile was 6 min (flight 27a, profile 2; see Table 4). With its true air speed of $20 \mathrm{~m} \mathrm{~s}^{-1}$,

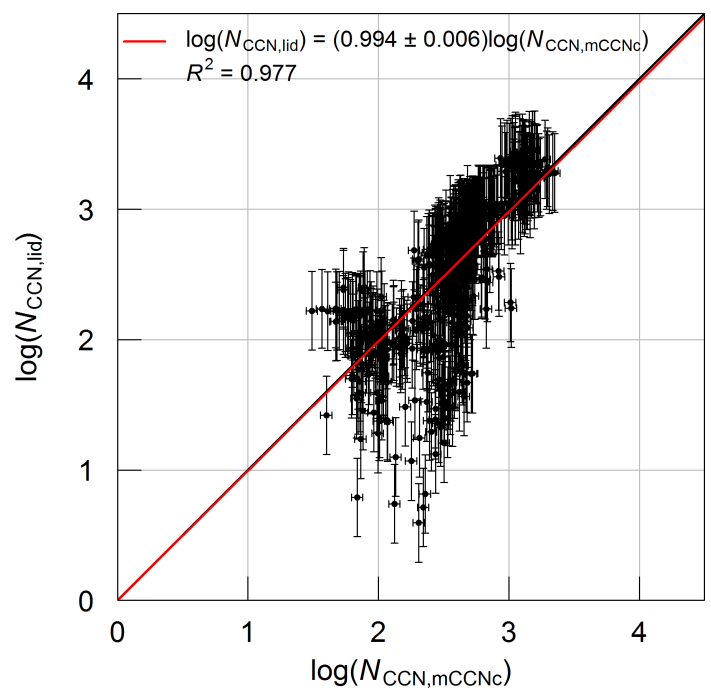

Figure 12. Correlation of the logarithmized (base 10) CCN-NC derived with the approach of Mamouri and Ansmann (2016) $\left(N_{\mathrm{CCN}, \text { lid }}\right)$ and directly measured with the mCCNc on ACTOS $\left(N_{\mathrm{CCN}, \mathrm{mCCNc}}\right)$ for six profiles conducted during three flights $(14 \mathrm{a}$, $14 \mathrm{~b}$, and 27a). Each profile has its associated lidar profile. Red line represents the line of fit and the black line the $1: 1$ line. Error bars represent the uncertainty of the lidar-based approach of a factor of 2 and the $10 \%$ uncertainty of the mCCNc on ACTOS.

ACTOS passes a horizontal distance of about $7.2 \mathrm{~km}$ within this period. Therefore, parts of the profile were not flown within the FOV of the lidar and therefore the lidar might not capture aerosol features observed by ACTOS.

\subsection{Intercomparison of optical parameters}

As an example, a comparison of in situ based calculated and lidar-observed profiles of aerosol optical properties for three legs of flight $14 \mathrm{~b}$ will be presented in this section. Afterwards, a summary of all investigated horizontal legs is given.

\subsubsection{Vertical structure during the flights}

Using the example of a profile from flight $14 \mathrm{~b}$, we first illustrate the vertical structure of the atmosphere in the investigated area. Figure 13 shows the vertical structure of in situ measured RH and $T$ in panel (a) and the aerosol particle number concentration measured by the CPC (NCPC) on ACTOS and by integrating the OPSS number size distribution NOPSS in panel (b). Furthermore, the vertical profiles of the particle backscatter coefficient derived with the lidar ( $\sigma_{\text {bsc, lid }}$; colored solid lines) and with the Mie calculations calculated for legs D, E, and F ( $\sigma_{\mathrm{bsc}}$, mie; colored dots with error bars) for the three lidar wavelengths are shown in panel (c). Additionally, profiles of the particle extinction coefficient are shown for both lidar derived and Mie based in panel (d). The shaded area around the lidar profiles indicates the assumed $15 \%$ uncertainty and the dashed lines with the respec- 


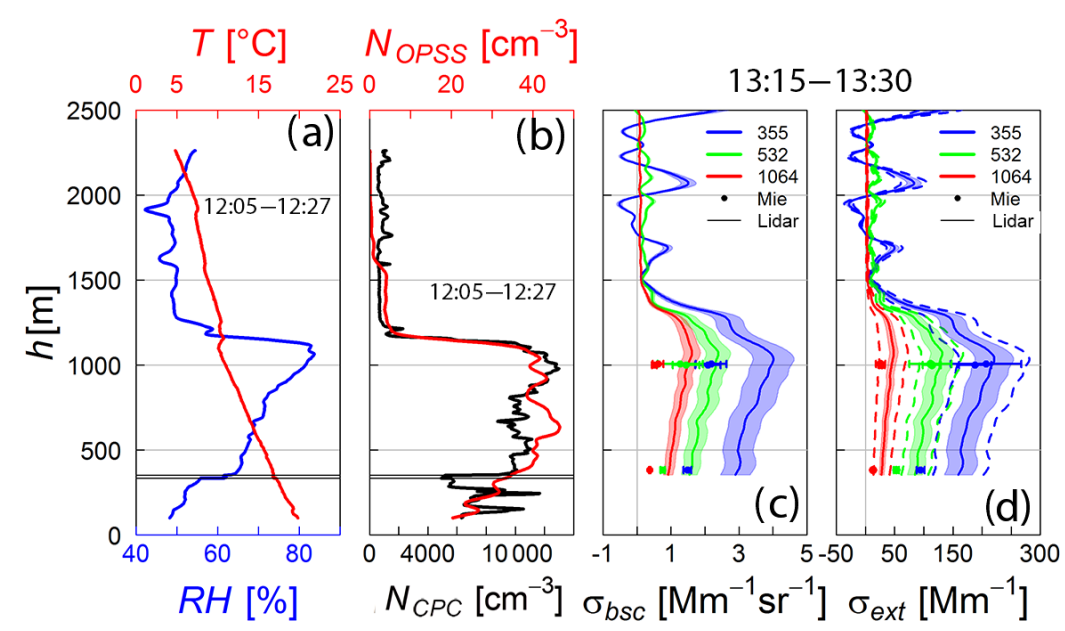

Figure 13. Panel (a) shows the profiles of the ambient relative humidity (RH, blue) and temperature ( $T$, red), whereas panel (b) illustrates the PNC derived with the CPC on ACTOS ( $N_{\mathrm{CPC}}$, black) and the PNC derived with the OPSS ( $N_{\text {OPSS }}$, red). The black thin horizontal lines in panels (a) and (b) mark the height where the profile was composed out of several vertical parts of flight 14b. The profile was flown between 12:05 and 12:27 UTC in the beginning of the flight. Panels (c) and (d) display the lidar-based particle light backscatter coefficient $\left(\sigma_{\text {bsc, lid }}(\lambda)\right)$ and the particle light extinction coefficient $\left(\sigma_{\text {ext, lid }}(\lambda)\right)$ for three wavelengths (355 (blue), 532 (green), and $1064 \mathrm{~nm}($ red)) averaged over the period 13:15-13:30 UTC of 14 September. $\sigma_{\text {bsc, lid }}(\lambda)$ and $\sigma_{\text {ext, lid }}(\lambda)$ were smoothed (algorithm uses every sixth data point) within 350 and $2500 \mathrm{~m}$ height. Also, the results of the airborne-based particle light backscatter $\left(\sigma_{\text {bsc, mie }}(\lambda)\right)$ and extinction coefficient $\left(\sigma_{\text {ext, mie }}(\lambda)\right)$ are shown as colored dots for three different wavelengths (coloring same as for the lidar-based values). The error bars of the dots indicate the 3 times the standard deviation of the mean value over 50 runs of the Mie algorithm calculations. The shaded area around the lidar profiles marks the $15 \%$ error. The solid lines in the extinction panel (d) represent the profile for the extinction calculated out of the backscattering using the LR presented here ( $55 \mathrm{sr}$ for 355 and $532 \mathrm{~nm}, 30 \mathrm{sr}$ for $1064 \mathrm{~nm}$ ). The dashed line signs the extinction profile using a LR土 $15 \mathrm{sr}$.

tive colors around the lidar-based extinction profiles indicate the derived particle extinction coefficient profile calculated by using the particle backscatter coefficient profiles with LR \pm 15 sr larger and smaller, respectively.

In this example, the profiles of $T$ and RH show an inversion at approximately $1200 \mathrm{~m}$. This inversion is also characterized by a sharp decrease in both $N_{\mathrm{CPC}}$ and $N_{\mathrm{OPSS}}$ by a factor of 12 and 8 , respectively. The RH drops from around 85 to $50 \%$. Up to this height the layer is characterized by a steady increase of the RH from 45 to $85 \%$. Below the inversion, up to a height of around $330 \mathrm{~m} N_{\text {OPSS }}$ increases from 18 to $36 \mathrm{~cm}^{-3} \cdot N_{\mathrm{CPC}}$ shows a high variability in this first part of the profile, maybe due to helicopter exhausts released during the ascent of the helicopter. Above the height of $330 \mathrm{~m} N_{\mathrm{CPC}}$ and $N_{\text {OPSS }}$ show a value of around 10000 to $13000 \mathrm{~cm}^{-3}$ and 40 to $45 \mathrm{~cm}^{-3}$, respectively, whereby $N_{\mathrm{CPC}}$ is $30 \%$ larger at the top of the mixing layer then in $330 \mathrm{~m}$. For each of the three investigated wavelengths $\sigma_{\mathrm{bsc}}$, lid and $\sigma_{\text {ext, lid }}$ increase up to a height of $1100 \mathrm{~m}$ followed by a decrease up to a height of $1500 \mathrm{~m}$. In contrast to the sharp decrease in the first both panels, presenting a "snapshot" of the atmosphere, the slight, smooth decrease of the measured optical coefficients at the top of the mixing layer results from the averaging of the lidar measurements between 13:15 and 13:30 UTC. In this period the mixing layer is still developing (see Fig. 3) and thus the layer with an increased PNC is still growing.
Figure 13 shows a clear correlation of RH and the particle light backscatter and extinction coefficient. While $N_{\text {OPSS }}$ is almost constant between 330 and $1100 \mathrm{~m}$ altitude, RH increases with height and due to the hygroscopic growth the cross section (more surface of the particles scatters and absorbs more light) of the aerosol particles increases as well. Quantitatively, the Mie calculation also produces larger particle light backscatter and extinction coefficients (dots with error bars in panel c) under conditions with an elevated RH. The conditions during leg E (smaller RH) led to a smaller $\sigma_{\text {bsc, mie }}$ and $\sigma_{\text {ext, mie }}$ than during legs $\mathrm{D}$ and $\mathrm{F}$.

During this campaign, we found a qualitatively similar structure also in the other investigated flights, but the quantity of the shown parameters, for instance the height of the PBL and the PNC within the PBL, was different.

Because of the constant multiplication of $\sigma_{\mathrm{bsc}}$, lid with the LR, the general behavior of the particle light extinction measured by the lidar does not differ from the backscatter measurements. The relative difference between the extinction at 1064 to $532 \mathrm{~nm}$ and $355 \mathrm{~nm}$ is different due to the smaller LR.

\subsubsection{Discussion of backscatter coefficient closure}

Figure 13 shows that $\sigma_{\mathrm{bsc}}$, mie is smaller than $\sigma_{\mathrm{bsc}}$, lid for each of the shown legs and wavelengths. Even within the considered uncertainties, measurements and model do not agree 
with each other. It should be noted that we use the term agreement when the uncertainty ranges ( 3 times the SD in the case of the Mie model and $15 \%$ in the case of the lidar) overlap. An underestimation of $\sigma_{\text {bsc }}$ by the Mie calculation may result from the non-detected particle size range between 226 and $356 \mathrm{~nm}$, so that the integration method (trapezoidal) may underestimate the particle light backscatter coefficient in this size range. More importantly, however, we expect that the setup used on ACTOS does not detect particles with an optical diameter larger than $2.8 \mu \mathrm{m}$ and thus those particles are not considered in the Mie calculations as well. Particles with a diameter about 6 times larger than the incoming wavelength are most effective in backscattering (Fig. A1, largest backscatter efficiency at a size parameter of $\sim 19$ ). For the here investigated wavelengths particles with a diameter of $\sim 2 \mu \mathrm{m}(355 \mathrm{~nm}), \sim 3.2 \mu \mathrm{m}(532 \mathrm{~nm})$ and $\sim 6 \mu \mathrm{m}$ would be most effective. In particular, for 532 and $1064 \mathrm{~nm}$ these particles were not detected with the setup used. In contrast, the lidar detects all aerosol particles.

For example, we have calculated the particle backscatter for a monodisperse aerosol in dry state at a wavelength of 355, 532, and $1064 \mathrm{~nm}$. The same conditions applied here as in the horizontal leg $\mathrm{F}$ of flight $14 \mathrm{~b}$. The monodisperse size distribution was created with Eq. (12):

$$
\begin{aligned}
& \frac{\mathrm{d} N}{\mathrm{~d} \log D_{\mathrm{p}}}\left(D_{\mathrm{p}}\right)= \\
& \frac{N}{\sqrt{2 \pi} \log _{10}(\sigma)} \exp \left[-\frac{1}{2}\left(\frac{\log _{10}\left(\frac{D_{\mathrm{p}}}{\bar{D}_{\mathrm{p}}}\right)}{\log _{10}(\sigma)}\right)\right],
\end{aligned}
$$

where $N$ denotes the total particle number concentration in the mode, $\sigma$ the geometric SD, and $\overline{D_{\mathrm{p}}}$ the median diameter of the mode. With a volume fraction of 0.037 of eBC, a $N$ of $2 \mathrm{~cm}^{-3}$, a $\sigma$ of 1.1 , and $\overline{D_{\mathrm{p}}}$ of $2 \mu \mathrm{m}$ would cause a particle backscattering of $1.44(355 \mathrm{~nm}), 2.29(532 \mathrm{~nm})$, and $1.7 \mathrm{Mm}^{-1} \mathrm{sr}^{-1}(1064 \mathrm{~nm})$. For monodisperse aerosol with a median diameter of $5 \mu \mathrm{m}$ the calculation result in 5.39 $(355 \mathrm{~nm}), 2.09(532 \mathrm{~nm})$, and $9.09 \mathrm{Mm}^{-1} \mathrm{sr}^{-1}(1064 \mathrm{~nm})$. This configuration is more than enough to close the gap between the calculations and the observations.

Additionally, the horizontal distance between the lidar and ACTOS could be a reason because the columnar measurements of the lidar just partly match with the flight pattern of ACTOS. Finally, the lidar resolves the horizontal inhomogeneity in the atmosphere (see Fig. 9) in a vertical manner. Therefore, features of these horizontal inhomogeneities can be detected by ACTOS and the lidar at different times. This might explain disagreements of the Mie calculations and the lidar measurements.

Table B1 lists the values of each $\sigma_{\text {bsc }}$ data point that we investigated in this study and which are shown in Fig. 14. For the lidar measurements the $15 \%$ error and for the calculated values 3 times the standard are shown. For fields marked with "-", the signal-to-noise ratio of the lidar within the respective height region was too low to retrieve aerosol properties with high accuracy and therefore was not used for comparison.

For each flight, $\sigma_{\text {bsc }}$ is larger within the mixing layer than above. For flights $14 \mathrm{~b}$ and $27 \mathrm{a}$ at least two legs were located within the mixing layer. During flight $14 \mathrm{~b} \sigma_{\mathrm{bsc}}$ shows a low variation within the mixing layer. The $\sigma_{\mathrm{bsc}}$, derived from lidar measurements during legs $\mathrm{D}$ and F, performed at the same heights ( $999 \pm 16$ and $1006 \pm 17 \mathrm{~m}$ ), varying within $5 \%$ (see Table B1). $\sigma_{\mathrm{bsc}}$, lid, 355 of leg E, also measured within the mixing layer $\left(\overline{h_{\text {leg }}}=382 \mathrm{~m}\right)$, is around $20 \%$ smaller than in legs $\mathrm{D}$ and $\mathrm{F}$. This can be explained by an enhanced hygroscopic growth due to the larger $\mathrm{RH}$ at around $1000 \mathrm{~m}$ than at $380 \mathrm{~m}$ (see Fig. 13). In contrast, the $\sigma_{\mathrm{bsc}}$, lid of leg B is around 5 times larger than that derived for leg $\mathrm{D}$ of flight $27 \mathrm{a}$, but measured at the same height. This can be explained by the difference in the time of measurement of around $65 \mathrm{~min}$. While in leg B most of the aerosol mass is trapped within the mixing layer in the lowest $300 \mathrm{~m}$, the thickness of the ML reached approximately $750 \mathrm{~m}$ height at the measurement time of leg D. Due to turbulent mixing of cleaner air from above the ML, trapped aerosol was diluted and therefore the PNC decreased. At $532 \mathrm{~nm}$ wavelength leg B of flight 14a shows larger values of $\sigma_{\mathrm{bsc}}$, lid than at $355 \mathrm{~nm}$. Due to the low value of the measured $\sigma_{\mathrm{bsc}}$ this could be explained by the measurement uncertainty.

Figure 14 shows the correlation between the calculated and the measured $\sigma_{\mathrm{bsc}}$ of all investigated legs. The error bars represent the considered uncertainties of the lidar and 3 times the SD of the Mie algorithm's mean. According to flight time and mean flight height of the horizontal legs, we choose the respective lidar profile to compare the Mie-based values with the lidar profiles at the respective height (see Fig. 13). The lidar value at the respective height was derived by linear interpolation between to height steps of the lidar profiles. For all wavelengths, $\sigma_{\mathrm{bsc}}$, mie shows on average smaller values than $\sigma_{\mathrm{bsc}}$, lid. For measurements at a wavelength of 355 and $532 \mathrm{~nm}$, values of $\sigma_{\mathrm{bsc}}$, mie are about $30 \%$ smaller $(355 \mathrm{~nm} 29.5 \%$ and $532 \mathrm{~nm} 27.4 \%)$ and for $\lambda=1064 \mathrm{~nm}$ $50.1 \%$ smaller. This results might be due to the fact that particles most efficient in backscattering were not observed with the airborne setup.

In addition, it is clearly visible that on each flight the backscatter coefficients are smaller above the PBL (see Table B1) compared to those within the PBL. This is caused by the lower aerosol concentration above the mixing layer.

To summarize, lidar measurements match with the particle light backscatter coefficients based on the airborne in situ measurements in $30 \%$ of the considered cases (see Table B1) for $355 \mathrm{~nm}$ and in $40 \%$ of the cases for 532 and $1064 \mathrm{~nm}$. Still, the conversion from in situ measurements to $\sigma_{\text {bsc }}$ is possible with the underlying assumptions and partly agrees with direct measurements of the lidar system used here. Nevertheless, an improved measurement setup is certainly needed. In particular within the PBL, the determination of the PNSD is important, as stated by Kent et al. (1983), especially for 


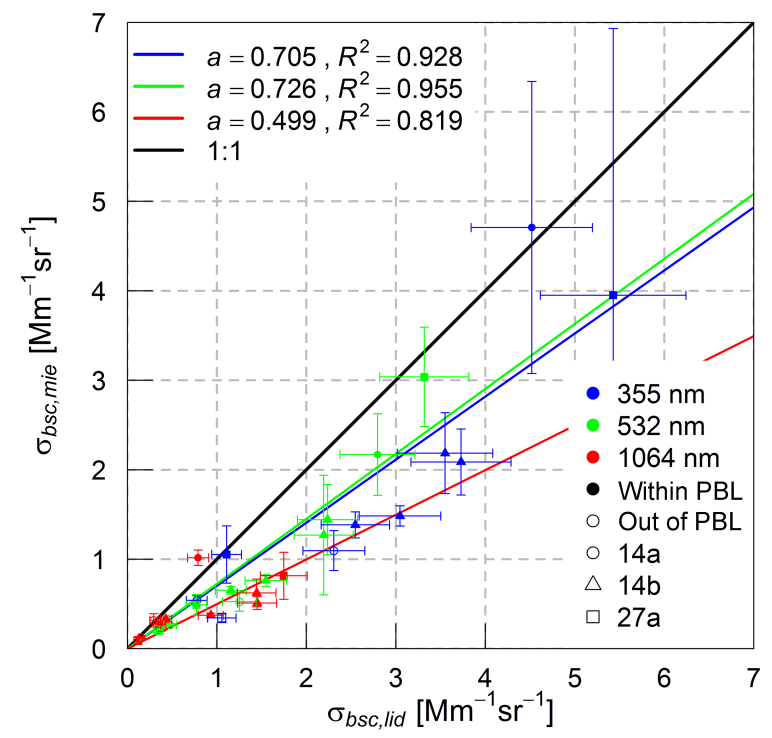

Figure 14. Scatterplot of the airborne-based $\left(\sigma_{\mathrm{bsc}}\right.$, mie $)$ and the lidar-based $\left(\sigma_{\mathrm{bsc}}\right.$, lid $)$ particle light backscatter coefficients for all horizontal legs during the investigated days for wavelengths $\lambda=$ 355 (blue), 532 (green), and $1064 \mathrm{~nm}$ (red). The error bars represent the assumed $15 \%$ error for the lidar measurements and 3 times the standard deviation of the mean of the result of the Mie calculations. The colored lines represent the linear correlation of both parameters, with $a$ the slope of the fit and $R^{2}$ the correlation coefficient. The black one is the $1: 1$ line. Filled symbols indicate data points determined within the planetary boundary layer, whereas empty symbols indicate data points above. Circles represent data points determined during flight $14 \mathrm{a}$; triangles indicate flight $14 \mathrm{~b}$ and squares 27 a.

particles larger than $1 \mu \mathrm{m}$, although they considered $\sigma_{\mathrm{bsc}}$ for light of a wavelength of $10.6 \mu \mathrm{m}$. With our setup, we cover particles up to a size of $2.8 \mu \mathrm{m}$ in optical diameter. The upper cutoff of the inlet system was unfortunately at about $2 \mu \mathrm{m}$. In contrast, the lidar system detects all particle sizes. Therefore, prevalent particles with a diameter larger than the upper detection limit of the airborne in situ instrumentation are not considered in the optical calculation and so the backscattering is underestimated by the Mie algorithm. An OPSS with a larger detection range as well as larger upper sampling cutoff of the inlet could overcome this problem, as the example calculation for monodisperse aerosol mentioned above shows.

\subsubsection{Discussion of the extinction coefficient closure}

\section{5 and $532 \mathrm{~nm}$ wavelength}

For leg D and leg E, both located roughly $1000 \mathrm{~m}$ aboveground, $\sigma_{\text {ext, mie }}$ coincides with $\sigma_{\text {ext, lid }}$ for $\lambda=355$ and $532 \mathrm{~nm}$. The $\sigma_{\text {ext, mie }}$ of leg $\mathrm{E}$ is for all wavelengths smaller than the lidar-based $\sigma_{\text {ext }}$. For $355 \mathrm{~nm} \sigma_{\text {ext, mie }}$ is $44 \%$ and for $532 \mathrm{~nm} 38 \%$ smaller than $\sigma_{\text {ext, lid. A smaller LR could }}$

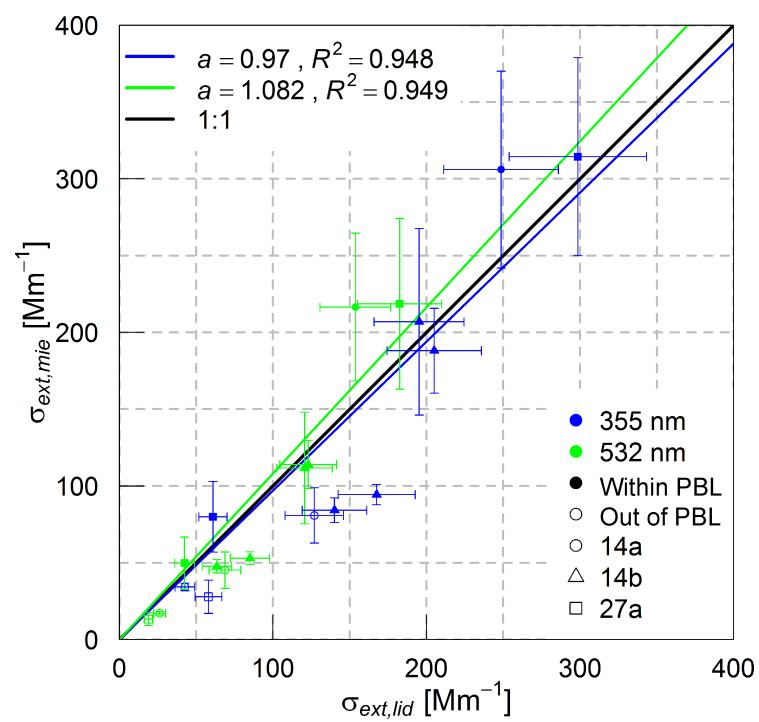

Figure 15. Scatterplot of the airborne-based ( $\left.\sigma_{\text {ext, mie }}\right)$ and the lidar-based $\left(\sigma_{\text {ext, lid }}\right)$ particle light extinction coefficients for all horizontal legs during the investigated days for the wavelengths $\lambda=355$ (blue) and $532 \mathrm{~nm}$ (green). $\sigma_{\text {ext, lid derived with a LR of }}$ $55 \mathrm{sr}$. The error bars represent the assumed $15 \%$ error for the lidar measurements and 3 times the standard deviation of the mean of the result of the Mie calculations. Lines and symbols as in Fig. 14.

explain this discrepancy, but $\mathrm{LR}_{\text {mie }}$ for 355 and $532 \mathrm{~nm}$ is larger than the $55 \mathrm{sr}$ used here, which is possibly explained by the underestimation of $\sigma_{\text {bsc }}$ by the Mie calculations. Clean marine aerosol, as stated in Bréon (2013), provides a LR of around $25 \mathrm{sr}$ for $670 \mathrm{~nm}$, which is slightly larger than in the study of Groß et al. (2011), who found that a transported clean marine aerosol (measured at Praia, Cape Verde Islands) causes slightly wavelength-dependent LRs of 14 to $24 \mathrm{sr}$ at $355 \mathrm{~nm}$ and 17 to $19 \mathrm{sr}$ at $532 \mathrm{~nm}$ wavelength. Also, Groß et al. (2011) showed that a mixture of biomassburning aerosol and dust is characterized by a wavelengthindependent LR of 57 to $98 \mathrm{sr}$ for 532 and $355 \mathrm{~nm}$. Based on 10 years of Raman lidar observations in Europe, Asia, and Africa Müller et al. (2007) characterized the LR for several aerosol types within the PBL or in the free troposphere. For $532 \mathrm{~nm}$ lidar systems within the PBL lidar ratios were found between $23 \pm 3 \mathrm{sr}$ for a marine aerosol and $55 \pm 5 \mathrm{sr}$ for mineral dust of the Sahara. For $355 \mathrm{~nm}$ they found lidar ratios between $55 \pm 6 \mathrm{sr}$ for mineral dust of the Sahara and $58 \pm 12 \mathrm{sr}$ for urban or anthropogenic haze aerosol in central Europe. The investigations for central Europe are of special interest because they are representative of the Raman lidar dataset used here. In this case they found a LR of $53 \pm 11 \mathrm{sr}$ for $532 \mathrm{~nm}$ and $58 \pm 12 \mathrm{sr}$ for $355 \mathrm{~nm}$. Omar et al. (2009) present a satellite-based study, which provides model-based lidar ratios for different aerosol types for 532 and $1064 \mathrm{~nm}$. For the cases of clean continental, polluted continental, and polluted dust the lidar ratios for $1064 \mathrm{~nm}$ were $30 \mathrm{sr}$. 


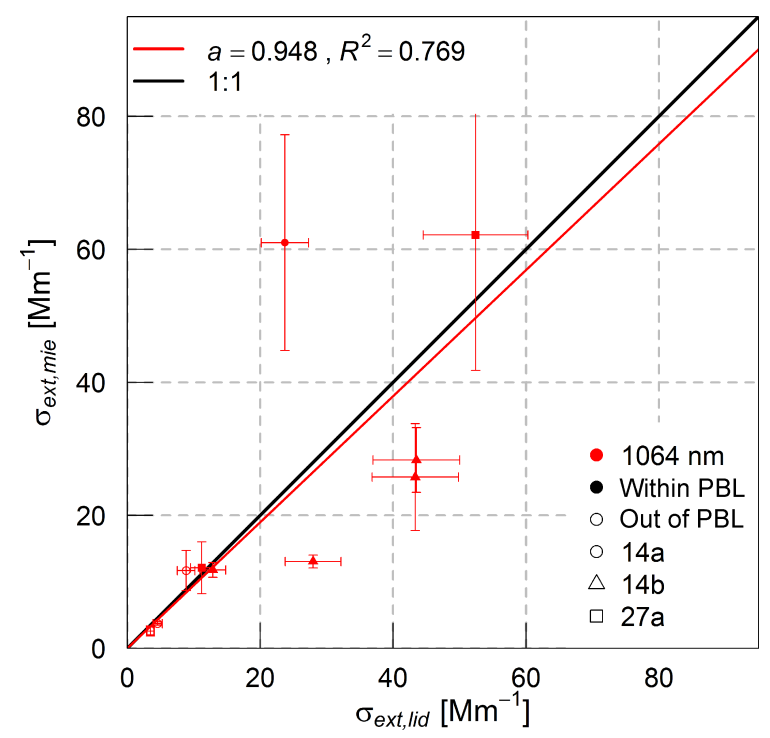

Figure 16. Scatterplot of particle light extinction coefficient derived with Mie calculations ( $\left.\sigma_{\text {ext, mie }}\right)$ and lidar-based $\left(\sigma_{\text {ext, lid }}\right)$ for all horizontal legs during the investigated days for $\lambda=1064 \mathrm{~nm}$.

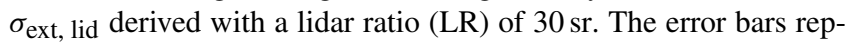
resent the assumed $15 \%$ error for the lidar measurements and 3 times the standard deviation of the mean of the result of the Mie calculations. Lines and symbols as in Figs. 14 and 15.

Considering all measurement points of this study, the particle light extinction coefficient shows a different behavior than the particle light backscatter coefficient converted from the aerosol in situ measurements, which is significantly smaller than the lidar-derived particle light backscatter coefficient. In Fig. 15, the correlation of $\sigma_{\text {ext, lid }}$ and $\sigma_{\text {ext, mie }}$ is shown (error bars are the same as in Fig. 14). $\sigma_{\text {ext, lid }}$ and $\sigma_{\text {ext, mie }}$ agree within $8.2 \%$ with each other with a high correlation coefficient $R^{2}$ of 0.948 for 355 and 0.949 for $532 \mathrm{~nm}$, respectively. For $\lambda=355 \mathrm{~nm}$ the Mie algorithm calculates on average $3.5 \%$ smaller values than the lidar. This implies that the LR used here for 355 and $532 \mathrm{~nm}$ is valid. In contrast, the calculated particle light extinction coefficient is overestimated compared to the lidar-based particle extinction on average by $8.2 \%$ for $532 \mathrm{~nm}$. According to the values in Table B2 $60 \%$ of the $\sigma_{\text {ext, mie }}$ values agree with the measured $\sigma_{\text {ext }}$ at 355 and $532 \mathrm{~nm}$. While Groß et al. (2011) found wavelength-independent LR for 355 and $532 \mathrm{~nm}$, the algorithm used here produces different LR for the different wavelengths and horizontal legs, especially for 1064 and $355 / 532 \mathrm{~nm}$. On average, the LR at 355 and $532 \mathrm{~nm}$ is $69.9 \pm 13.3$ and $70.9 \pm 21.2$, respectively, which is larger than the assumed fixed LR. An underestimation of $\sigma_{\text {bsc }}$ due to the in situ sampling setup has to be considered and so these LR might be too high. Nevertheless, these LR agree with Groß et al. (2011), and, furthermore, the $\mathrm{LR}_{\mathrm{mie}}$ of around $70 \mathrm{sr}$ agrees with a LR of $58 \pm 12$ for $355 \mathrm{~nm}$ as given in Müller et al. (2007).

\section{$1064 \mathrm{~nm}$ wavelength}

The scatterplot of $\sigma_{\text {ext, lid }}$ and $\sigma_{\text {ext, mie }}$ for $1064 \mathrm{~nm}$ is given in Fig. 16. On average, the algorithm calculates $5.2 \%$ smaller values than derived by the lidar, but compared to 355 and $532 \mathrm{~nm}$ the correlation coefficient $R^{2}$ is significantly smaller (0.769). In the range of 0 to $20 \mathrm{Mm}^{-1}$ in $\sigma_{\mathrm{ext}}$ for $1064 \mathrm{~nm}$, the correlation is close to the $1: 1$ line (black solid line). Above this range, the correlation is less significant.

As an example, the Mie calculations are $53 \%$ smaller than the lidar-based particle extinction coefficients during leg $\mathrm{E}$ in flight $14 \mathrm{~b}$, whereas the Mie calculations are significantly larger for leg D of flight $14 \mathrm{a}$ (see Fig. 16; $\sigma_{\text {ext, mie }}=61.0 \pm$ $\left.16 \mathrm{Mm}^{-1}, \sigma_{\text {ext, lid }}=23.7 \pm 3.6 \mathrm{Mm}^{-1}\right)$. This overestimation of $\sigma_{\text {ext }}$ is also clearly visible for the wavelengths 355 and $532 \mathrm{~nm}$.

For legs D and $\mathrm{F}$ of flight $14 \mathrm{~b}$ the Mie-based values are $35 \%$ (leg D) and $42 \%$ (leg F) smaller than derived by the lidar. Within the range of the LR $( \pm 15 \mathrm{sr})$, the in situ and lidar-based particle light extinction coefficients coincide (see Fig. 13). The Mie-based $L_{\text {mie }}$ is 19.6 and 20.3 sr for leg D and leg $\mathrm{F}$, respectively. By using these values for calculation $\sigma_{\text {ext, lid }}$ from $\sigma_{\text {bsc, lid }}$ the $\sigma_{\text {ext, lid }}$ becomes 28.4 (leg D of 14b) and $29.4 \mathrm{Mm}^{-1}$ (leg F of 14b). This agrees with a $\sigma_{\text {ext, mie }}$ of $28.3 \pm 4.9 \mathrm{Mm}^{-1}$ derived during leg $\mathrm{D}$ and $25.8 \pm 8.0 \mathrm{Mm}^{-1}$ for leg F. For $1064 \mathrm{~nm}$ and leg $\mathrm{E}$ of flight $14 \mathrm{~b}$ the $\mathrm{LR}_{\text {mie }}$ is $17.1 \mathrm{sr}$. Using this LR $\sigma_{\text {ext, mie }}$ and $\sigma_{\text {ext, lid }}$ agree with each other within the uncertainties. Overall for $1064 \mathrm{~nm} 60 \%$ of $\sigma_{\text {ext, mie }}$ are in agreement with $\sigma_{\text {ext, lid }}$, using a LR of $30 \mathrm{sr}$. A summary of all investigated data points of $\sigma_{\text {ext }}$ for all three investigated wavelengths is given in Table B2.

\subsubsection{Influence of a different $\kappa$ measurement}

Kristensen et al. (2016) described a method to derive the hygroscopicity based on PNSD and total CCN-NC measurements (here with the mCCNc on ACTOS) at a certain supersaturation. Applied to the airborne dataset used here, nonreliable values of the particle hygroscopicity with a high SD were ascertained. Although the $\mathrm{CCN}-\mathrm{NC}$ seems to be very stable with height and time during the day (see Fig. 10), the method of Kristensen et al. (2016), which is based on the evaluation of the critical diameter, is very sensitive to the PNSD. The size resolution, the low counting statistic, and the non-observed size range in the PNSD (between 226 and $356 \mathrm{~nm}$ ), derived with the MPSS and OPSS on ACTOS, lead to high variations in the calculated critical diameter and thus a variation in the particle hygroscopicity, resulting in unreasonable high or low hygroscopicity parameters. Measurements of CCN-NC are available at ground and overall they are representative of higher altitudes (see Fig. 10), but their temporal resolution is lower than that of the groundbased chemical measurement. Furthermore, the hygroscopicity determined by the $\mathrm{CCNc}$ is only valid in the size range of the critical diameter. Calculations of the aerosol optical 
Table 5. Mean $\kappa$ for the ground-based measurements of the $\mathrm{CCNc}$ and Q-ACSM recorded between 08:00 and 15:00 UTC for the here investigated days.

\begin{tabular}{lcc}
\hline Date & $\kappa_{\mathrm{CCNc}}$ & $\kappa_{\mathrm{Q}-\mathrm{ACSM}}$ \\
\hline 14 Sep 2013 & $0.33 \pm 0.05$ & $0.43 \pm 0.03$ \\
27 Sep 2013 & $0.24 \pm 0.06$ & $0.41 \pm 0.03$ \\
\hline
\end{tabular}

properties under ambient conditions may therefore not be as representative as calculations with hygroscopicity from the Q-ACSM measurements.

Based on the ground-based CCN-NC measurements, the hygroscopicity of the aerosol particles was also derived. The resulting $\kappa$ from both methods is shown in Table 5. For the two days considered in this study, $\mathrm{CCNc}$ measurements on the ground led to lower values than the Q-ACSM measurements. Similar results were also observed by Martin et al. (2011) in the case of Arctic summer aerosol. They predicted on the basis of ASM (aerosol mass spectrometer) measurements consistently higher CCN-NC (correlated to hygroscopicity) than were measured with a $\mathrm{CCNC}$ for various supersaturations.

Organics could lead to an overestimation of the Q-ACSMbased hygroscopicity. Martin et al. (2011) obtained the best agreements when they regarded the organic substances as almost insoluble in water, which could indicate that in our case either the water-insoluble material was not detected or the detected organic substances had a lower hygroscopicity. In addition, both measurements may differ, since the Q-ACSM detects the aerosol in its completeness (PM1), while, as mentioned above, the hygroscopicity of $\mathrm{CCNc}$ measurements is only valid for the critical diameter range. A comparison of the correlation of the Mie-based aerosol optical properties derived with both approaches, the chemical composition and the CCNc-based, and the lidar-based aerosol optical properties is given in Table 6 . Table 6 provides parameters describing the correlation function $\sigma_{\text {mie }}=a \sigma_{\text {lid }}$ with its respective correlation coefficient $R^{2}$ for the Mie calculations using the $\kappa$ based on both approaches .

Compared with the chemical composition approach, the hygroscopicity taken from the ground-based CCN-NC measurements (see Table 5) leads to smaller ambient state optical properties (see Table 6). This is caused by a lower simulated growth of the aerosol particles due to the smaller hygroscopicity and therefore a lower cross section of the grown aerosol particles.

The general assumption of a constant $\kappa$ over all sizes in both approaches may not be justified. Size-resolved $\kappa$ might reduce the errors in the simulation of the hygroscopic growth and so reduces the uncertainties in the aerosol optical properties. A more satisfying approach would be to apply sizeresolved measurements of the aerosol particle growth factor or hygroscopicity on the derived airborne PNSD since the
Table 6. Parameters of the correlation of the Mie-based and the lidar-based optical properties. Hygroscopicity derived on the basis of the chemical composition and CCNc measurements on the ground. $a$ is the slope of the linear fit and $R^{2}$ is the correlation coefficient.

\begin{tabular}{lccc|cc}
\hline & & \multicolumn{2}{c|}{ Extinction } & \multicolumn{2}{c}{ Backscattering } \\
\cline { 3 - 6 } & $\lambda[\mathrm{nm}]$ & $a$ & $R^{2}$ & $a$ & $R^{2}$ \\
\hline Composition & 355 & 0.970 & 0.948 & 0.705 & 0.928 \\
based & 532 & 1.082 & 0.949 & 0.726 & 0.955 \\
& 1064 & 0.948 & 0.769 & 0.499 & 0.819 \\
\hline CCN based & 355 & 0.833 & 0.955 & 0.586 & 0.935 \\
& 532 & 0.910 & 0.959 & 0.590 & 0.975 \\
& 1064 & 0.757 & 0.776 & 0.450 & 0.782 \\
\hline
\end{tabular}

chemical composition of the aerosol particle varies with their size, depending on the origin of the aerosol particles.

\section{Summary and conclusions}

To investigate optical properties of aerosol particles in ambient state, an intensive field study was conducted as part of HOPE at the central European research observatory Melpitz, Germany. Aerosol particle light backscatter and extinction coefficients, based on highly spatiotemporally resolved vertical and horizontal aerosol measurements, have been compared to profiles of such aerosol optical properties at three wavelengths derived with remote sensing instruments. To be able to do this, the hygroscopic growth of aerosol particles was simulated using the hygroscopicity parameter $\kappa$ derived from ground-based chemical composition and $\mathrm{CCN}-$ $\mathrm{NC}$ measurements.

In this study, ground-based measurements of the PNC were found to be not always representative of higher atmospheric layers within the planetary boundary layer. In particular, new particle formation events in the residual layer (Wehner et al., 2010) can lead to a higher PNC and vertical variation inside the PBL. These elevated aerosol PNCs are not connected with ground-based measurements. However, transported air masses on the ground with a higher PNC can be decoupled from higher atmospheric layers and so the ground-based measurements also do not entirely represent elevated atmospheric layers - at least in the cases presented here. Nevertheless, in a well-mixed PBL, ground-based measurements provide a good estimate of the aerosol particle properties within the PBL.

The CCN-NC was also variable within the developing planetary boundary layer since entrainment processes at the top of the PBL can led to an increased CCN-NC, especially close to the top of the PBL, which was not captured by ground-based measurements. 
For three investigated flights, profiles of logarithmized (base 10) CCN-NC derived with the approach of Mamouri and Ansmann (2016) were compared with airborne in situ measurements of CCN-NC (logarithmized with base 10) and showed a surprisingly good agreement within $1 \%$ (lidar approach is lower) with a correlation coefficient of 0.977 . Although different supersaturations have been considered $(0.2 \%$ in situ and $0.15 \%$ lidar approach) and the lidar-based approach of Mamouri and Ansmann (2016) underlies uncertainties of a factor of about 2, the approach is a helpful tool to evaluate $\mathrm{CCN}-\mathrm{NC}$ with the lidar.

Furthermore, comparisons of Mie-theory-based and lidarbased particle light backscatter coefficients implies that the setup used here cannot provide a complete database to reproduce the "real" particle light backscatter coefficient since the investigated size range seems to be too small. This can be explained by the behavior of the backscatter efficiency of aerosol particles in the narrow scattering angle window in $180^{\circ}$ direction (see Fig. A1; high backscatter efficiency of particles around 6 times larger in diameter than the incoming radiation).

Within the uncertainty ranges, the particle light backscatter coefficients on the basis of the airborne in situ measurements agree with the measured $\sigma_{\text {bsc }}$ in up to $40 \%$ of the cases. On average, the algorithm used here retrieves 29.5, 27.4 , and $50.1 \%$ smaller $\sigma_{\mathrm{bsc}}$ compared to the measured ones at 355,532 , and $1064 \mathrm{~nm}$. In contrast, the conversion from airborne in situ aerosol measurements to $\sigma_{\text {ext }}$ yields promising results. For 355 and $532 \mathrm{~nm}$, the Mie-based $\sigma_{\text {ext }}$ reproduces the measured $\sigma_{\text {ext }}$ within $8.2 \%$ deviation and with a high correlation coefficient $\left(R^{2}>0.94\right)$. On average a LR of $55 \mathrm{sr}$ for 355 and $532 \mathrm{~nm}$ is applicable for the aerosol type investigated here.
In contrast, the knowledge of LR at $1064 \mathrm{~nm}$ is rare from direct active lidar measurements. First measurements to evaluate the LR at $1064 \mathrm{~nm}$ have been done by Haarig et al. (2016) with a rotational Raman lidar for a cirrus cloud case. In this cirrus case, they derived a LR for $1064 \mathrm{~nm}$ of $38 \pm 5 \mathrm{sr}$. The study presented here shows that a LR of $30 \mathrm{sr}$ provides on average a good agreement between Mie-based and lidar-based $\sigma_{\text {ext }}$ for the presented cases. This is also shown in the model-based study of Omar et al. (2009) for clean and polluted continental and polluted dust aerosol (LR of $30 \mathrm{sr}$ ). However, the algorithm used here provided an average LR for $1064 \mathrm{~nm}$ of $15.8 \pm 6.7 \mathrm{sr}$ (3.8 and 28.1 minimum and maximum).

As a concluding remark, we state that particle extinction coefficients derived with the different methods agree within the uncertainties. Furthermore, long-term observed LR were confirmed with in situ measurements. However, a reliable modeling of particle backscattering requires a large coverage in terms of particle size when detecting the particle number size distribution.

Data availability. Data set and source codes underlying this work can be requested via email to the corresponding author. 


\section{Appendix A: Effectiveness of Mie scattering}

Mie scattering is most effective for particles in the size range of the wavelength of the incoming radiation. The ratio of particle size $\left(D_{\mathrm{p}}\right)$ and the wavelength of the incoming electromagnetic radiation $(\lambda)$ multiplied with $\pi$ is described as size parameter $x$. This parameter is defined as

$$
x=\pi \frac{D_{\mathrm{p}}}{\lambda} .
$$

Figure A1 shows the extinction, scattering, absorption, and backscatter efficiency $Q_{\text {ext, sca, abs, bsc depending on the size }}$ parameter $x$ for spherical layered particles. They consist of a core of eBC (volume fraction of 0.05 ) and a shell of lessabsorbing non-refractory water-soluble material. The refractive index of eBC and the less-absorbing material were taken from Table 3. For scattering, extinction, and absorption the maximum in the efficiency is reached for an $x$ of around 3. According Eq. (A1), this means the ratio of $D_{\mathrm{p}}$ and $\lambda$ is unity. The scattering efficiency narrows unity with an increase of $x$. In contrast, the backscatter efficiency is maximal for an $x$ of 19. As a result, the instrumentation, which detects the PNSD of the aerosol, has to cover a large size range of aerosol particles.

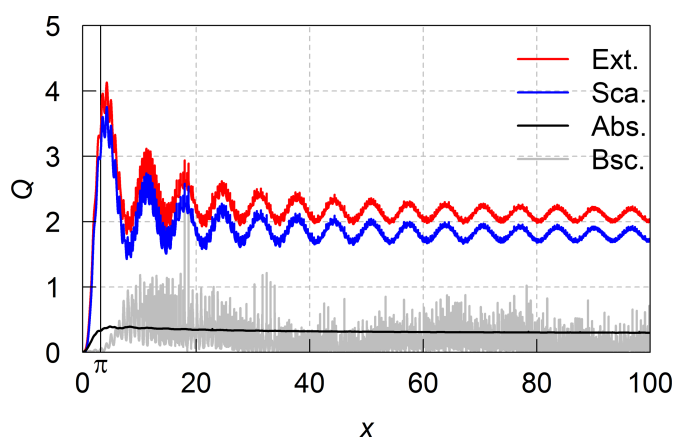

Figure A1. Mie-based particle light extinction, scattering, absorption, and backscatter efficiency $\left(Q_{\text {ext }}, Q_{\mathrm{sca}}, Q_{\mathrm{abs}}\right.$, and $\left.Q_{\mathrm{bsc}}\right)$, depending on the size parameter $x$ of layered aerosol particles with a core of eBC and a shell for a wavelength of $355 \mathrm{~nm}$. The volume fraction of $\mathrm{eBC}$ is 0.05 . The refractive index of core and shell were taken from Table 3. 
Appendix B: Tables of derived and measured optical coefficients

Table B1. Table shows the aerosol particle light backscatter coefficient $\left(\sigma_{\mathrm{bsc}}\right)$ derived with the lidar for the wavelengths 355 , 532, and $1064 \mathrm{~nm}$ for the mean height of each investigated leg. Also, the aerosol particle light backscatter coefficient converted from the airborne in situ aerosol measurements is printed for the respective lidar wavelength and horizontal leg. Additionally, it is shown whether the horizontal flight leg was conducted within or above the PBL. Values written in bold represent a disagreement between lidar and model, while normal script is an agreement. Brackets around the values indicate no lidar measurements available.

\begin{tabular}{|c|c|c|c|c|c|c|c|c|c|}
\hline \multirow[b]{3}{*}{ Flight } & \multirow[b]{3}{*}{ Leg } & \multirow[b]{3}{*}{ PBL } & \multirow[b]{3}{*}{$h_{\text {leg }}[\mathrm{m}]$} & \multicolumn{3}{|c|}{$\begin{array}{c}\text { Lidar } \\
\sigma_{\mathrm{bsc}}(\lambda) \pm 15 \%\left[\mathrm{Mm}^{-1} \mathrm{sr}^{-1}\right]\end{array}$} & \multicolumn{3}{|c|}{$\begin{array}{c}\text { Mie-based } \\
\sigma_{\mathrm{bsc}}(\lambda) \pm 3 \sigma_{\sigma_{\mathrm{bsc}}(\lambda)}\left[\mathrm{Mm}^{-1} \mathrm{sr}^{-1}\right]\end{array}$} \\
\hline & & & & & $\lambda$ & & & $\lambda$ & \\
\hline & & & & $355 \mathrm{~nm}$ & $532 \mathrm{~nm}$ & $1064 \mathrm{~nm}$ & $355 \mathrm{~nm}$ & $532 \mathrm{~nm}$ & $1064 \mathrm{~nm}$ \\
\hline $14 \mathrm{a}$ & A & no & 605 & $2.31 \pm 0.35$ & $1.25 \pm 0.19$ & $0.295 \pm 0.044$ & $1.10 \pm 0.22$ & $0.527 \pm 0.11$ & $0.317 \pm 0.074$ \\
\hline $14 \mathrm{a}$ & $\mathrm{B}$ & no & 1602 & - & - & - & $(0.302 \pm 0.04)$ & $(0.152 \pm 0.015)$ & $(0.08 \pm 0.014)$ \\
\hline $14 \mathrm{a}$ & $\mathrm{C}$ & no & 994 & $0.776 \pm 0.12$ & $0.477 \pm 0.072$ & $0.152 \pm 0.023$ & $0.541 \pm 0.051$ & $0.267 \pm 0.014$ & $0.12 \pm 0.0093$ \\
\hline $14 \mathrm{a}$ & $\mathrm{D}$ & yes & 378 & $4.52 \pm 0.68$ & $2.80 \pm 0.42$ & $0.719 \pm 0.12$ & $4.71 \pm 1.63$ & $2.17 \pm 0.46$ & $1.02 \pm 0.086$ \\
\hline $14 \mathrm{~b}$ & A & yes & 366 & $2.55 \pm 0.38$ & $1.16 \pm 0.17$ & $0.429 \pm 0.064$ & $1.38 \pm 0.15$ & $0.654 \pm 0.044$ & $0.33 \pm 0.043$ \\
\hline $14 b$ & $\mathrm{~B}$ & no & 2244 & - & - & - & $(0.0209 \pm 0.0011)$ & $(0.0129 \pm 0.00075)$ & $(0.0022 \pm 0.00017)$ \\
\hline $14 b$ & $\mathrm{C}$ & no & 1619 & - & - & - & $(0.238 \pm 0.059)$ & $(0.115 \pm 0.017)$ & $(0.0494 \pm 0.011)$ \\
\hline $14 b$ & $\mathrm{D}$ & yes & 999 & $3.73 \pm 0.56$ & $2.24 \pm 0.34$ & $1.45 \pm 0.22$ & $2.09 \pm 0.37$ & $1.44 \pm 0.39$ & $0.511 \pm 0.071$ \\
\hline $14 b$ & E & yes & 382 & $3.05 \pm 0.46$ & $1.55 \pm 0.23$ & $0.932 \pm 0.14$ & $1.48 \pm 0.11$ & $0.762 \pm 0.066$ & $0.374 \pm 0.024$ \\
\hline $14 b$ & $\mathrm{~F}$ & yes & 1006 & $3.55 \pm 0.53$ & $2.19 \pm 0.33$ & $1.44 \pm 0.22$ & $2.19 \pm 0.45$ & $1.27 \pm 0.67$ & $0.624 \pm 0.16$ \\
\hline $27 \mathrm{a}$ & A & no & 372 & $1.06 \pm 0.16$ & $0.345 \pm 0.05$ & $0.116 \pm 0.017$ & $0.344 \pm 0.052$ & $0.205 \pm 0.024$ & $0.0912 \pm 0.037$ \\
\hline $27 \mathrm{a}$ & $\mathrm{B}$ & yes & 195 & $5.43 \pm 0.81$ & $3.32 \pm 0.5$ & $1.75 \pm 0.26$ & $3.95 \pm 3.0$ & $3.04 \pm 0.56$ & $0.815 \pm 0.26$ \\
\hline $27 \mathrm{a}$ & $\mathrm{C}$ & no & 1559 & - & - & - & $(0.046 \pm 0.017)$ & $(0.0302 \pm 0.007)$ & $(0.00626 \pm 0.003)$ \\
\hline $27 \mathrm{a}$ & $\mathrm{D}$ & yes & 212 & $1.11 \pm 0.17$ & $0.772 \pm 0.12$ & $0.374 \pm 0.056$ & $1.05 \pm 0.32$ & $0.49 \pm 0.12$ & $0.271 \pm 0.077$ \\
\hline
\end{tabular}

Table B2. Table shows the aerosol particle light extinction coefficient $\left(\sigma_{\text {ext }}\right)$ derived with the lidar for the wavelengths 355 , 532, and $1064 \mathrm{~nm}$ for the mean height of each investigated leg. Also, the aerosol particle light extinction coefficient converted from the airborne in situ aerosol measurements is printed for the respective lidar wavelength and horizontal leg. Additionally, it is shown whether the horizontal flight leg was conducted within or above the PBL. Values written in bold represent a disagreement between lidar and model, while normal script is an agreement. Brackets around the values indicate no lidar measurements available.

\begin{tabular}{|c|c|c|c|c|c|c|c|c|c|}
\hline \multirow{2}{*}{ Flight } & \multirow{2}{*}{ Leg } & \multirow{2}{*}{ PBL } & \multirow{2}{*}{$h_{\text {leg }}[\mathrm{m}]$} & \multicolumn{3}{|c|}{$\begin{array}{c}\text { Lidar } \\
\sigma_{\text {ext }}(\lambda) \pm 15 \%\left[\mathrm{Mm}^{-1} \mathrm{sr}^{-1}\right]\end{array}$} & \multicolumn{3}{|c|}{$\begin{array}{c}\text { Mie-based } \\
\sigma_{\text {ext }}(\lambda) \pm 3 \sigma_{\sigma_{\text {ext }}(\lambda)}\left[\mathrm{Mm}^{-1} \mathrm{sr}^{-1}\right]\end{array}$} \\
\hline & & & & \multicolumn{3}{|c|}{$\lambda$} & \multicolumn{3}{|c|}{$\lambda$} \\
\hline $14 \mathrm{a}$ & A & no & 605 & $127 \pm 19$ & $68.8 \pm 10$ & $8.86 \pm 1.3$ & $80.8 \pm 18$ & $45.2 \pm 12$ & $11.7 \pm 3.0$ \\
\hline $14 \mathrm{a}$ & $\mathrm{B}$ & no & 1602 & - & - & - & $(21.7 \pm 3.7)$ & $(12.1 \pm 2.0)$ & $(2.69 \pm 0.48)$ \\
\hline $14 b$ & A & yes & 366 & 140. \pm 21 & $63.6 \pm 9.5$ & $12.9 \pm 1.9$ & $84.2 \pm 8.1$ & $47.7 \pm 4.3$ & $11.8 \pm 1.1$ \\
\hline $14 b$ & $\mathrm{~B}$ & no & 2244 & - & - & - & $(0.939 \pm 0.063)$ & $(0.333 \pm 0.027)$ & $(0.0494 \pm 0.0061)$ \\
\hline $14 b$ & $\mathrm{C}$ & no & 1619 & - & - & - & $(14.3 \pm 3.6)$ & $(6.53 \pm 1.2)$ & $(1.22 \pm 0.22)$ \\
\hline $14 b$ & $\mathrm{D}$ & yes & 999 & $205 \pm 31$ & $123 \pm 18$ & $43.5 \pm 6.5$ & $188 \pm 28$ & $114 \pm 16$ & $28.3 \pm 4.9$ \\
\hline $14 b$ & $\mathrm{E}$ & yes & 382 & $168 \pm 25$ & $85.1 \pm 13$ & $28.0 \pm 4.2$ & $94.4 \pm 6.6$ & $53.0 \pm 4.2$ & $13.1 \pm 0.97$ \\
\hline $27 \mathrm{a}$ & $\mathrm{D}$ & yes & 212 & $61.0 \pm 9.1$ & $42.5 \pm 6.4$ & $11.2 \pm 1.7$ & $80.0 \pm 23$ & $49.8 \pm 17$ & $12.1 \pm 3.9$ \\
\hline
\end{tabular}


Competing interests. The authors declare that they have no conflict of interest.

Special issue statement. This article is part of the special issue "HD(CP)2 Observational Prototype Experiment (ACP/AMT interjournal SI)". It is not associated with a conference.

Acknowledgements. We are grateful for the competent help of the technicians Thomas Conrad and Astrid Hofmann and we thank all the other employees of TROPOS who have supported us so energetically and courageously before, during, and after the campaign and have made the campaign a full success. Furthermore, we are very thankful to the helicopter pilots Alwin Völlmer and Jürgen Schütz of the Rotorflug airservices $\mathrm{GmbH} \& \mathrm{Co}$. $\mathrm{KGaA}$ for the secure flights. The authors furthermore thank Dieter Schell of enviscope $\mathrm{GmbH}$ for his expertise. Furthermore, we are thankful to Gregory C. Roberts of Scripps Institution of Oceanography (Center for Atmospheric Sciences, La Jolla, USA) for providing the custom-built mini cloud condensation nuclei counter. This study was mainly carried out in the project $\mathrm{HD}(\mathrm{CP})^{2}$ funded by the German Ministry for Education and Research. We specifically acknowledge the $\mathrm{HD}(\mathrm{CP})^{2}$ project 01LK1212C (TROPOS). The authors gratefully acknowledge the NOAA Air Resources Laboratory (ARL) for the provision of the HYSPLIT transport and dispersion model and/or READY website (http://www.ready.noaa.gov) used in this publication. The authors acknowledge support through ACTRIS-2 under grant agreement no. 654109 from the European Union's Horizon 2020 research and innovation programme.

Edited by: Herman Russchenberg

Reviewed by: two anonymous referees

\section{References}

Altstädter, B., Platis, A., Wehner, B., Scholtz, A., Wildmann, N., Hermann, M., Käthner, R., Baars, H., Bange, J., and Lampert, A.: ALADINA - an unmanned research aircraft for observing vertical and horizontal distributions of ultrafine particles within the atmospheric boundary layer, Atmos. Meas. Tech., 8, 16271639, https://doi.org/10.5194/amt-8-1627-2015, 2015.

Ansmann, A., Wandinger, U., Riebesell, M., Weitkamp, C. and Michaelis, W.: Independent measurement of extinction and backscatter profiles in cirrus clouds by using a combined Raman elastic-backscatter lidar, Appl. Optics, 31, 7113, https://doi.org/10.1364/ao.31.007113, 1992.

Ansmann, A., Tesche, M., Groß, S., Freudenthaler, V., Seifert, P., Hiebsch, A., Schmidt, J., Wandinger, U., Mattis, I., Müller, D., and Wiegner, M.: The 16 April 2010 major volcanic ash plume over central Europe: EARLINET lidar and AERONET photometer observations at Leipzig and Munich, Germany, Geophys. Res. Lett., 37, L13810, https://doi.org/10.1029/2010GL043809, 2010.

Baars, H., Kanitz, T., Engelmann, R., Althausen, D., Heese, B., Komppula, M., Preißler, J., Tesche, M., Ansmann, A., Wandinger, U., Lim, J.-H., Ahn, J. Y., Stachlewska, I. S., Amiridis, V., Marinou, E., Seifert, P., Hofer, J., Skupin, A.,
Schneider, F., Bohlmann, S., Foth, A., Bley, S., Pfüller, A., Giannakaki, E., Lihavainen, H., Viisanen, Y., Hooda, R. K., Pereira, S. N., Bortoli, D., Wagner, F., Mattis, I., Janicka, L., Markowicz, K. M., Achtert, P., Artaxo, P., Pauliquevis, T., Souza, R. A. F., Sharma, V. P., van Zyl, P. G., Beukes, J. P., Sun, J., Rohwer, E. G., Deng, R., Mamouri, R.-E., and Zamorano, F.: An overview of the first decade of PollyNET: an emerging network of automated Raman-polarization lidars for continuous aerosol profiling, Atmos. Chem. Phys., 16, 5111-5137, https://doi.org/10.5194/acp16-5111-2016, 2016.

Birmili, W., Stratmann, F., and Wiedensohler, A.: Design of a DMA-based size spectrometer for a large particle size range and stable operation, J. Aerosol Sci., 30, 549-553, https://doi.org/10.1016/S0021-8502(98)00047-0, 1999.

Birmili, W., Weinhold, K., Rasch, F., Sonntag, A., Sun, J., Merkel, M., Wiedensohler, A., Bastian, S., Schladitz, A., Löschau, G., Cyrys, J., Pitz, M., Gu, J., Kusch, T., Flentje, H., Quass, U., Kaminski, H., Kuhlbusch, T. A. J., Meinhardt, F., Schwerin, A., Bath, O., Ries, L., Gerwig, H., Wirtz, K., and Fiebig, M.: Longterm observations of tropospheric particle number size distributions and equivalent black carbon mass concentrations in the German Ultrafine Aerosol Network (GUAN), Earth Syst. Sci. Data, 8, 355-382, https://doi.org/10.5194/essd-8-355-2016, 2016.

Bohren, C. F. and Huffman, D. R.: Absorption and Scattering of Light by Small Particles, Chapter: Absorption and Scattering by a Sphere, John Wiley and Sons Ltd., 82-129, https://doi.org/10.1002/9783527618156.ch4, 1983.

Bond, T. C., Doherty, S. J., Fahey, D. W., Forster, P. M., Berntsen, T., DeAngelo, B. J., Flanner, M. G., Ghan, S., Kärcher, B., Koch, D., Kinne, S., Kondo, Y., Quinn, P. K., Sarofim, M. C., Schultz, M. G., Schulz, M., Venkataraman, C., Zhang, H., Zhang, S., Bellouin, N., Guttikunda, S. K., Hopke, P. K., Jacobson, M. Z., Kaiser, J. W., Klimont, Z., Lohmann, U., Schwarz, J. P., Shindell, D., Storelvmo, T., Warren, S. G., and Zender, C. S.: Bounding the role of black carbon in the climate system: A scientific assessment, J. Geophys. Res.Atmos., 118, 5380-5552, https://doi.org/10.1002/jgrd.50171, 2013.

Breon, F.: CLIMATE: How Do Aerosols Affect Cloudiness and Climate?, Science, 313, 623-624, https://doi.org/10.1126/science.1131668, 2006.

Bréon, F.-M.: Aerosol extinction-to-backscatter ratio derived from passive satellite measurements, Atmos. Chem. Phys., 13, 89478954, https://doi.org/10.5194/acp-13-8947-2013, 2013.

Chauvigné, A., Sellegri, K., Hervo, M., Montoux, N., Freville, P., and Goloub, P.: Comparison of the aerosol optical properties and size distribution retrieved by sun photometer with in situ measurements at midlatitude, Atmos. Meas. Tech., 9, 4569-4585, https://doi.org/10.5194/amt-9-4569-2016, 2016.

Crippa, M., Canonaco, F., Lanz, V. A., Äijälä, M., Allan, J. D., Carbone, S., Capes, G., Ceburnis, D., Dall'Osto, M., Day, D. A., DeCarlo, P. F., Ehn, M., Eriksson, A., Freney, E., Hildebrandt Ruiz, L., Hillamo, R., Jimenez, J. L., Junninen, H., Kiendler-Scharr, A., Kortelainen, A.-M., Kulmala, M., Laaksonen, A., Mensah, A. A., Mohr, C., Nemitz, E., O’Dowd, C., Ovadnevaite, J., Pandis, S. N., Petäjä, T., Poulain, L., Saarikoski, S., Sellegri, K., Swietlicki, E., Tiitta, P., Worsnop, D. R., Baltensperger, U., and Prévôt, A. S. H.: Organic aerosol components derived from 25 AMS data sets across Europe using a consistent ME-2 based 
source apportionment approach, Atmos. Chem. Phys., 14, 61596176, https://doi.org/10.5194/acp-14-6159-2014, 2014.

Cross, E. S., Slowik, J. G., Davidovits, P., Allan, J. D., Worsnop, D. R., Jayne, J. T., Lewis, D. K., Canagaratna, M., and Onasch, T. B.: Laboratory and ambient particle density determinations using light scattering in conjunction with aerosol mass spectrometry, Aerosol Sci. Tech., 41, 343-359, https://doi.org/10.1080/02786820701199736, 2007.

DeCarlo, P. F., Slowik, J. G., Worsnop, D. R., Davidovits, P., and Jimenez, J. L.: Particle morphology and density characterization by combined mobility and aerodynamic diameter measurements. Part 1: Theory, Aerosol Sci. Tech., 38, 1185-1205, https://doi.org/10.1080/027868290903907, 2004.

Ditas, F., Shaw, R. A., Siebert, H., Simmel, M., Wehner, B., and Wiedensohler, A.: Aerosols-cloud microphysicsthermodynamics-turbulence: evaluating supersaturation in a marine stratocumulus cloud, Atmos. Chem. Phys., 12, 2459-2468, https://doi.org/10.5194/acp-12-2459-2012, 2012.

Dombrovsky, L. A.: The mie solution for spherical particles, https://doi.org/10.1615/thermopedia.000137, Thermopedia, 2011.

Dubovik, O., Holben, B., Eck, T. F., Smirnov, A., Kaufman, Y. J., King, M. D., and Slutsker, I.: Variability of absorption and optical properties of key aerosol types observed in worldwide locations, J. Atmos. Sci, 59, 590-608, https://doi.org/10.1175/15200469(2002)059<0590:VOAAOP>2.0.CO;2, 2002.

Engelmann, R., Kanitz, T., Baars, H., Heese, B., Althausen, D., Skupin, A., Wandinger, U., Komppula, M., Stachlewska, I. S., Amiridis, V., Marinou, E., Mattis, I., Linné, H., and Ansmann, A.: The automated multiwavelength Raman polarization and water-vapor lidar Polly XT: the neXT generation, Atmos. Meas. Tech., 9, 1767-1784, https://doi.org/10.5194/amt-9-1767-2016, 2016.

Ferrare, R. A., Turner, D. D., Brasseur, L. H., Feltz, W. F., Dubovik, O., and Tooman, T. P.: Raman lidar measurements of the aerosol extinction-to-backscatter ratio over the Southern Great Plains, J. Geophys. Res.-Atmos., 106, 20333-20347, https://doi.org/10.1029/2000JD000144, 2001.

Ferrero, L., Castelli, M., Ferrini, B. S., Moscatelli, M., Perrone, M. G., Sangiorgi, G., D’Angelo, L., Rovelli, G., Moroni, B., Scardazza, F., Mocnik, G., Bolzacchini, E., Petitta, M., and Cappelletti, D.: Impact of black carbon aerosol over Italian basin valleys: high-resolution measurements along vertical profiles, radiative forcing and heating rate, Atmos. Chem. Phys., 14, 96419664, https://doi.org/10.5194/acp-14-9641-2014, 2014.

Fröhlich, R., Crenn, V., Setyan, A., Belis, C. A., Canonaco, F., Favez, O., Riffault, V., Slowik, J. G., Aas, W., Aijälä, M., Alastuey, A., Artiñano, B., Bonnaire, N., Bozzetti, C., Bressi, M., Carbone, C., Coz, E., Croteau, P. L., Cubison, M. J., EsserGietl, J. K., Green, D. C., Gros, V., Heikkinen, L., Herrmann, H., Jayne, J. T., Lunder, C. R., Minguillón, M. C., Močnik, G., O’Dowd, C. D., Ovadnevaite, J., Petralia, E., Poulain, L., Priestman, M., Ripoll, A., Sarda-Estève, R., Wiedensohler, A., Baltensperger, U., Sciare, J., and Prévôt, A. S. H.: ACTRIS ACSM intercomparison - Part 2: Intercomparison of ME-2 organic source apportionment results from 15 individual, co-located aerosol mass spectrometers, Atmos. Meas. Tech., 8, 2555-2576, https://doi.org/10.5194/amt-8-2555-2015, 2015.
Fuchs, N.: On the stationary charge distribution on aerosol particles in a bipolar ionic atmosphere, Geofis. Pura Appl., 56, 185-193, https://doi.org/10.1007/BF01993343, 1963.

Groß, S., Tesche, M., Freudenthaler, V., Toledano, C., Wiegner, M., Ansmann, A., Althausen, D., and Seefeldner, M.: Characterization of Saharan dust, marine aerosols and mixtures of biomassburning aerosols and dust by means of multi-wavelength depolarization and Raman lidar measurements during SAMUM 2, Tellus B, 63, 706-724, https://doi.org/10.1111/j.16000889.2011.00556.x, 2011.

Groß, S., Esselborn, M., Weinzierl, B., Wirth, M., Fix, A., and Petzold, A.: Aerosol classification by airborne high spectral resolution lidar observations, Atmos. Chem. Phys., 13, 2487-2505, https://doi.org/10.5194/acp-13-2487-2013, 2013.

Gysel, M., Crosier, J., Topping, D. O., Whitehead, J. D., Bower, K. N., Cubison, M. J., Williams, P. I., Flynn, M. J., McFiggans, G. B., and Coe, H.: Closure study between chemical composition and hygroscopic growth of aerosol particles during TORCH2, Atmos. Chem. Phys., 7, 6131-6144, https://doi.org/10.5194/acp7-6131-2007, 2007.

Haarig, M., Engelmann, R., Ansmann, A., Veselovskii, I., Whiteman, D. N., and Althausen, D.: $1064 \mathrm{~nm}$ rotational Raman lidar for particle extinction and lidar-ratio profiling: cirrus case study, Atmos. Meas. Tech., 9, 4269-4278, https://doi.org/10.5194/amt9-4269-2016, 2016.

Henning, S., Dieckmann, K., Ignatius, K., Schäfer, M., Zedler, P., Harris, E., Sinha, B., van Pinxteren, D., Mertes, S., Birmili, W., Merkel, M., Wu, Z., Wiedensohler, A., Wex, H., Herrmann, H., and Stratmann, F.: Influence of cloud processing on $\mathrm{CCN}$ activation behaviour in the Thuringian Forest, Germany during HCCT-2010, Atmos. Chem. Phys., 14, 7859-7868, https://doi.org/10.5194/acp-14-7859-2014, 2014.

Hovorka, J., Leoni, C., Dočekalová, V., Ondráček, J., and Zíková, N.: Aerosol distribution in the planetary boundary layer aloft a residential area, IOP C. Ser. Earth Env., 44, https://doi.org/10.1088/1755-1315/44/5/052017, 2016.

IPCC: Climate Change 2007: Synthesis Report. Contribution of Working Groups I, II and III to the Fourth Assessment Report of the Intergovernmental Panel on Climate Change, Core Writing Team, edited by: Pachauri, R. K. and Reisinger, A., IPCC, Geneva, Switzerland, 104 pp., 2007.

IPCC: Cubasch, U., Wuebbles, D., Chen, D., Facchini, M. C., Frame, D., Mahowald, N., and Winther, J.-G.: Introduction, in: Climate Change 2013: The Physical Science Basis. Contribution of Working Group I to the Fifth Assessment Report of the Intergovernmental Panel on Climate Change, edited by: Stocker, T. F., Qin, D., Plattner, G.-K., Tignor, M., Allen, S. K., Boschung, J., Nauels, A., Xia, Y., Bex, V., and Midgley, P. M., Cambridge University Press, Cambridge, UK and New York, NY, USA, 119158, https://doi.org/10.1017/CBO9781107415324.007, 2013.

Kahnert, M., Nousiainen, T., Lindqvist, H., and Ebert, M.: Optical properties of light absorbing carbon aggregates mixed with sulfate: assessment of different model geometries for climate forcing calculations, Opt. Express, 20, 10042-10058, https://doi.org/10.1364/OE.20.010042, 2012.

Kent, G., Yue, G. K., Farrukh, U. O., and Deepak, A.: Modeling atmospheric aerosol backscatter at $\mathrm{CO}_{2}$ laser wavelengths. 2: Modeled values in the atmosphere, Appl. Optics, 22, 1666-1670, https://doi.org/10.1364/AO.22.001666, 1983. 
Köhler, H.: The nucleus in and the growth of hygroscopic droplets, T. Faraday Soc., 32, 1152-1161, https://doi.org/10.1039/TF9363201152, 1936.

Kristensen, T. B., Müller, T., Kandler, K., Benker, N., Hartmann, M., Prospero, J. M., Wiedensohler, A., and Stratmann, F.: Properties of cloud condensation nuclei $(\mathrm{CCN})$ in the trade wind marine boundary layer of the western North Atlantic, Atmos. Chem. Phys., 16, 2675-2688, https://doi.org/10.5194/acp-162675-2016, 2016.

Kulkarni, P., Baron, P. A., and Willeke, K.: Aerosol Measurement: Principles, Techniques, and Applications, John Wiley and Sons, Hoboken, N.J., https://doi.org/10.1002/9781118001684, 2011.

Lin, Z. J., Zhang, Z. S., Zhang, L., Tao, J., Zhang, R. J., Cao, J. J., Fan, S. J., and Zhang, Y. H.: An alternative method for estimating hygroscopic growth factor of aerosol light-scattering coefficient: a case study in an urban area of Guangzhou, South China, Atmos. Chem. Phys., 14, 7631-7644, https://doi.org/10.5194/acp14-7631-2014, 2014.

Lopatin, A., Dubovik, O., Chaikovsky, A., Goloub, P., Lapyonok, T., Tanré, D., and Litvinov, P.: Enhancement of aerosol characterization using synergy of lidar and sun-photometer coincident observations: the GARRLiC algorithm, Atmos. Meas. Tech., 6, 2065-2088, https://doi.org/10.5194/amt-6-2065-2013, 2013.

Lu, X., Jiang, Y., Zhang, X., Wang, X., Nasti, L., and Spinelli, N.: Retrieval of aerosol extinction-to-backscatter ratios by combining ground-based and space-borne lidar elastic scattering measurements, Opt. Express., 19, A72-A79, https://doi.org/10.1364/OE.19.000A72, 2011.

Ma, N., Birmili, W., Müller, T., Tuch, T., Cheng, Y. F., Xu, W. Y., Zhao, C. S., and Wiedensohler, A.: Tropospheric aerosol scattering and absorption over central Europe: a closure study for the dry particle state, Atmos. Chem. Phys., 14, 6241-6259, https://doi.org/10.5194/acp-14-6241-2014, 2014.

Macke, A., Seifert, P., Baars, H., Barthlott, C., Beekmans, C., Behrendt, A., Bohn, B., Brueck, M., Bühl, J., Crewell, S., Damian, T., Deneke, H., Düsing, S., Foth, A., Di Girolamo, P., Hammann, E., Heinze, R., Hirsikko, A., Kalisch, J., Kalthoff, N., Kinne, S., Kohler, M., Löhnert, U., Madhavan, B. L., Maurer, V., Muppa, S. K., Schween, J., Serikov, I., Siebert, H., Simmer, C., Späth, F., Steinke, S., Träumner, K., Trömel, S., Wehner, B., Wieser, A., Wulfmeyer, V., and Xie, X.: The $\mathrm{HD}(\mathrm{CP})^{2} \mathrm{Ob}-$ servational Prototype Experiment (HOPE) - an overview, Atmos. Chem. Phys., 17, 4887-4914, https://doi.org/10.5194/acp17-4887-2017, 2017.

Mamouri, R.-E. and Ansmann, A.: Potential of polarization lidar to provide profiles of $\mathrm{CCN}$ - and INP-relevant aerosol parameters, Atmos. Chem. Phys., 16, 5905-5931, https://doi.org/10.5194/acp-16-5905-2016, 2016.

Martin, M., Chang, R. Y.-W., Sierau, B., Sjogren, S., Swietlicki, E., Abbatt, J. P. D., Leck, C., and Lohmann, U.: Cloud condensation nuclei closure study on summer arctic aerosol, Atmos. Chem. Phys., 11, 11335-11350, https://doi.org/10.5194/acp-11-113352011, 2011.

Mattis, I., Ansmann, A., Müller, D., Wandinger, U., and Althausen, D.: Multiyear aerosol observations with dual-wavelength Raman lidar in the framework of EARLINET, J. Geophys. Res.-Atmos., 109, D13203, https://doi.org/10.1029/2004jd004600, 2004.

Mazzola, M., Busetto, M., Ferrero, L., Viola, A., and Cappelletti, D.: AGAP: an atmospheric gondola for aerosol profiling, Rendi- conti Lincei, 27, 105-113, https://doi.org/10.1007/s12210-0160514-x, 2016.

Mie, G.: Beiträge zur Optik trüber Medien, speziell kolloidaler Metalllösungen, Ann. Phys., 330, 377-445, https://doi.org/10.1002/andp.19083300302, 1908.

Müller, D., Wandinger, U., and Ansmann, A.: Microphysical particle parameters from extinction and backscatter lidar data by inversion with regularization: simulation, Appl. Optics, 38, 23582368, https://doi.org/10.1364/AO.38.002358, 1999.

Müller, D., Wagner, F., Wandinger, U., Ansmann, A., Wendisch, M., Althausen, D., and von Hoyningen-Huene, W.: Microphysical particle parameters from extinction and backscatter lidar data by inversion with regularization: experiment, Appl. Optics, 39, 1879-1892, https://doi.org/10.1364/AO.39.001879, 2000.

Müller, D., Ansmann, A., Mattis, I., Tesche, M., Wandinger, U., Althausen, D., and Pisani, G.: Aerosol-type-dependent lidar ratios observed with Raman lidar, J. Geophys. Res.-Atmos., 112, D16202, https://doi.org/10.1029/2006JD008292, 2007.

Müller, T., Henzing, J. S., de Leeuw, G., Wiedensohler, A., Alastuey, A., Angelov, H., Bizjak, M., Collaud Coen, M., Engström, J. E., Gruening, C., Hillamo, R., Hoffer, A., Imre, K., Ivanow, P., Jennings, G., Sun, J. Y., Kalivitis, N., Karlsson, H., Komppula, M., Laj, P., Li, S.-M., Lunder, C., Marinoni, A., Martins dos Santos, S., Moerman, M., Nowak, A., Ogren, J. A., Petzold, A., Pichon, J. M., Rodriquez, S., Sharma, S., Sheridan, P. J., Teinilä, K., Tuch, T., Viana, M., Virkkula, A., Weingartner, E., Wilhelm, R., and Wang, Y. Q.: Characterization and intercomparison of aerosol absorption photometers: result of two intercomparison workshops, Atmos. Meas. Tech., 4, 245-268, https://doi.org/10.5194/amt-4-245-2011, 2011.

Ng, N. L., Herndon, S. C., Trimborn, A., Canagaratna, M. R., Croteau, P., Onasch, T. B., Sueper, D., Worsnop, D. R., Zhang, Q., Sun, Y., and Jayne, J. T.: An Aerosol Chemical Speciation Monitor (ACSM) for routine monitoring of the composition and mass concentrations of ambient aerosol, Aerosol Sci. Tech., 45, 780-794, https://doi.org/10.1080/02786826.2011.560211, 2011.

Omar, A. H., Winker, D. M., Vaughan, M. A., Hu, Y., Trepte, C. R., Ferrare, R. A., Lee, K.-P., Hostetler, C. A., Kittaka, C., Rogers, R. R., Ferrare, R. A., Lee, K.-P., Kuehn, R. E., and Hostetler, C. A.: The CALIPSO automated aerosol classification and lidar ratio selection algorithm, J. Atmos. Ocean. Tech., 26, 1994-2014, https://doi.org/10.1175/2009JTECHA1231.1, 2009.

Petters, M. D. and Kreidenweis, S. M.: A single parameter representation of hygroscopic growth and cloud condensation nucleus activity, Atmos. Chem. Phys., 7, 1961-1971, https://doi.org/10.5194/acp-7-1961-2007, 2007.

Pfeifer, S., Birmili, W., Schladitz, A., Müller, T., Nowak, A., and Wiedensohler, A.: A fast and easy-to-implement inversion algorithm for mobility particle size spectrometers considering particle number size distribution information outside of the detection range, Atmos. Meas. Tech., 7, 95-105, https://doi.org/10.5194/amt-7-95-2014, 2014.

Pilinis, C., Pandis, S. N., and Seinfeld, J. H.: Sensitivity of direct climate forcing by atmospheric aerosols to aerosol size and composition, J. Geophys. Res.-Atmos., 100, 18739-18754, https://doi.org/10.1029/95JD02119, 1995. 
Pöschl, U.: Atmospheric aerosols: composition, transformation, climate and health effects, Angew. Chem. Int. Edit., 44, 7520-7540, https://doi.org/10.1002/anie.200501122, 2005.

Poulain, L., Birmili, W., Canonaco, F., Crippa, M., Wu, Z. J., Nordmann, S., Spindler, G., Prévôt, A. S. H., Wiedensohler, A., and Herrmann, H.: Chemical mass balance of $300^{\circ} \mathrm{C}$ non-volatile particles at the tropospheric research site Melpitz, Germany, Atmos. Chem. Phys., 14, 10145-10162, https://doi.org/10.5194/acp-14-10145-2014, 2014.

Ran, L., Deng, Z., Xu, X., Yan, P., Lin, W., Wang, Y., Tian, P., Wang, P., Pan, W., and Lu, D.: Vertical profiles of black carbon measured by a micro-aethalometer in summer in the North China Plain, Atmos. Chem. Phys., 16, 10441-10454, https://doi.org/10.5194/acp-16-10441-2016, 2016.

Roberts, G. C. and Nenes, A.: A continuous-flow streamwise thermal-gradient $\mathrm{CCN}$ chamber for atmospheric measurements, Aerosol Sci. Tech., 39, 206-221, https://doi.org/10.1080/027868290913988, 2005.

Rosati, B., Herrmann, E., Bucci, S., Fierli, F., Cairo, F., Gysel, M., Tillmann, R., Größ, J., Gobbi, G. P., Di Liberto, L., Di Donfrancesco, G., Wiedensohler, A., Weingartner, E., Virtanen, A., Mentel, T. F., and Baltensperger, U.: Studying the vertical aerosol extinction coefficient by comparing in situ airborne data and elastic backscatter lidar, Atmos. Chem. Phys., 16, 4539-4554, https://doi.org/10.5194/acp-16-4539-2016, 2016a.

Rosati, B., Gysel, M., Rubach, F., Mentel, T. F., Goger, B., Poulain, L., Schlag, P., Miettinen, P., Pajunoja, A., Virtanen, A., Klein Baltink, H., Henzing, J. S. B., Größ, J., Gobbi, G. P., Wiedensohler, A., Kiendler-Scharr, A., Decesari, S., Facchini, M. C., Weingartner, E., and Baltensperger, U.: Vertical profiling of aerosol hygroscopic properties in the planetary boundary layer during the PEGASOS campaigns, Atmos. Chem. Phys., 16, 7295-7315, https://doi.org/10.5194/acp-16-7295-2016, 2016 b.

Samset, B. H., Myhre, G., Schulz, M., Balkanski, Y., Bauer, S., Berntsen, T. K., Bian, H., Bellouin, N., Diehl, T., Easter, R. C., Ghan, S. J., Iversen, T., Kinne, S., Kirkevåg, A., Lamarque, J.-F., Lin, G., Liu, X., Penner, J. E., Seland, Ø., Skeie, R. B., Stier, P., Takemura, T., Tsigaridis, K., and Zhang, K.: Black carbon vertical profiles strongly affect its radiative forcing uncertainty, Atmos. Chem. Phys., 13, 2423-2434, https://doi.org/10.5194/acp13-2423-2013, 2013.

Schwartz, S., Charlson, R., Kahn, R., Ogren, J., and Rodhe, H.: Why Hasn't Earth Warmed as Much as Expected?, J. Climate, 23, 2453-2464, https://doi.org/10.1175/2009jcli3461.1, 2010.

Schwarz, A.: Aerosol typing over Europe and its benefits for the CALIPSO and EarthCARE missions - Statistical analysis based on multiwavelength aerosol lidar measurements from ground-based EARLINET stations and comparison to spaceborne CALIPSO data, PhD thesis, University of Leipzig, Germany, 2016.

Seinfeld, J. H. and Pandis, S. N.: Atmospheric Chemistry Physics, John Wiley and Sons, Inc., Hoboken, N.J., 2nd Edn., 2006.

Shinozuka, Y., Clarke, A. D., Nenes, A., Jefferson, A., Wood, R., McNaughton, C. S., Ström, J., Tunved, P., Redemann, J., Thornhill, K. L., Moore, R. H., Lathem, T. L., Lin, J. J., and Yoon, Y. J.: The relationship between cloud condensation nuclei $(\mathrm{CCN})$ concentration and light extinction of dried particles: indications of underlying aerosol processes and implications for satellite- based CCN estimates, Atmos. Chem. Phys., 15, 7585-7604, https://doi.org/10.5194/acp-15-7585-2015, 2015.

Siebert, H., Lehmann, K., Wendisch, M., Franke, H., Maser, R., Schell, D., Wei Saw, E., and Shaw, R.: Probing Finescale Dynamics and Microphysics of Clouds with HelicopterBorne Measurements, B. Am. Meteorol. Soc., 87, 1727-1738, https://doi.org/10.1175/bams-87-12-1727, 2006.

Spindler, G., Brüggemann, E., Gnauk, T., Grüner, A., Müller, K., and Herrmann, H.: A four-year size-segregated characterization study of particles PM, PM and PM depending on air mass origin at Melpitz, J. Atmos. Environ., 44, 164-173, https://doi.org/10.1016/j.atmosenv.2009.10.015, 2010.

Spindler, G., Grüner, A., Müller, K., Schlimper, S., and Herrmann, H.: Long-term size-segregated particle $\left(\mathrm{PM}_{10}, \mathrm{PM}_{2.5}\right.$, $\mathrm{PM}_{1}$ ) characterization study at Melpitz - influence of air mass inflow, weather conditions and season, J. Atmos. Chem., 70, 165195, https://doi.org/10.1007/s10874-013-9263-8, 2013.

Stein, A., Draxler, R., Rolph, G., Stunder, B., Cohen, M., and Ngan, F.: NOAA's HYSPLIT atmospheric transport and dispersion modeling system, B. Am. Meteorol. Soc., 96, 2059-2077, https://doi.org/10.1175/BAMS-D-14-00110.1, 2015.

Summa, D., Di Girolamo, P., Stelitano, D., and Cacciani, M.: Characterization of the planetary boundary layer height and structure by Raman lidar: comparison of different approaches, Atmos. Meas. Tech., 6, 3515-3525, https://doi.org/10.5194/amt-6-35152013, 2013.

Tao, Z., Liu, Z., Wu, D., McCormick, M. P., and Su, J.: Determination of aerosol extinction-to-backscatter ratios from simultaneous ground-based and spaceborne lidar measurements, Opt. Lett., 33, 2986-2988, https://doi.org/10.1364/OL.33.002986, 2008.

Tsekeri, A., Amiridis, V., Marenco, F., Nenes, A., Marinou, E., Solomos, S., Rosenberg, P., Trembath, J., Nott, G. J., Allan, J., Le Breton, M., Bacak, A., Coe, H., Percival, C., and Mihalopoulos, N.: Profiling aerosol optical, microphysical and hygroscopic properties in ambient conditions by combining in situ and remote sensing, Atmos. Meas. Tech., 10, 83-107, https://doi.org/10.5194/amt-10-83-2017, 2017.

Twomey, S.: The influence of pollution on the shortwave albedo of clouds, J. Atmos. Sci. 34, 1149-1152, $\quad$ https://doi.org/10.1175/15200469(1977)034<1149:TIOPOT>2.0.CO;2, 1977.

Vaughan, R. A. and Cracknell, A. P. (Eds.): Remote Sensing and Global Climate Change, Vol. 24, Springer Science \& Business Media, Berlin, Germany, https://doi.org/10.1007/9783-642-79287-8, 2013.

Väänänen, R., Krejci, R., Manninen, H. E., Manninen, A., Lampilahti, J., Buenrostro Mazon, S., Nieminen, T., Yli-Juuti, T., Kontkanen, J., Asmi, A., Aalto, P. P., Keronen, P., Pohja, T., O'Connor, E., Kerminen, V.-M., Petäjä, T., and Kulmala, M.: Vertical and horizontal variation of aerosol number size distribution in the boreal environment, Atmos. Chem. Phys. Discuss., https://doi.org/10.5194/acp-2016-556, in review, 2016.

Virkkula, A., Backman, J., Aalto, P. P., Hulkkonen, M., Riuttanen, L., Nieminen, T., dal Maso, M., Sogacheva, L., de Leeuw, G., and Kulmala, M.: Seasonal cycle, size dependencies, and source analyses of aerosol optical properties at the SMEAR II measurement station in Hyytiälä, Finland, Atmos. Chem. Phys., 11, 4445-4468, https://doi.org/10.5194/acp-11-4445-2011, 2011. 
Wandinger, U. and Ansmann, A.: Experimental determination of the lidar overlap profile with Raman lidar, Appl. Optics, 41, 511514, https://doi.org/10.1364/AO.41.000511, 2002.

Wandinger, U., Freudenthaler, V., Baars, H., Amodeo, A., Engelmann, R., Mattis, I., Groß, S., Pappalardo, G., Giunta, A., D’Amico, G., Chaikovsky, A., Osipenko, F., Slesar, A., Nicolae, D., Belegante, L., Talianu, C., Serikov, I., Linné, H., Jansen, F., Apituley, A., Wilson, K. M., de Graaf, M., Trickl, T., Giehl, H., Adam, M., Comerón, A., Muñoz-Porcar, C., Rocadenbosch, F., Sicard, M., Tomás, S., Lange, D., Kumar, D., Pujadas, M., Molero, F., Fernández, A. J., Alados-Arboledas, L., Bravo-Aranda, J. A., Navas-Guzmán, F., Guerrero-Rascado, J. L., Granados-Muñoz, M. J., Preißler, J., Wagner, F., Gausa, M., Grigorov, I., Stoyanov, D., Iarlori, M., Rizi, V., Spinelli, N., Boselli, A., Wang, X., Lo Feudo, T., Perrone, M. R., De Tomasi, F., and Burlizzi, P.: EARLINET instrument intercomparison campaigns: overview on strategy and results, Atmos. Meas. Tech., 9, 1001-1023, https://doi.org/10.5194/amt-9-1001-2016, 2016.

Wehner, B., Siebert, H., Ansmann, A., Ditas, F., Seifert, P., Stratmann, F., Wiedensohler, A., Apituley, A., Shaw, R. A., Manninen, H. E., and Kulmala, M.: Observations of turbulenceinduced new particle formation in the residual layer, Atmos. Chem. Phys., 10, 4319-4330, https://doi.org/10.5194/acp-104319-2010, 2010.

Wehner, B., Werner, F., Ditas, F., Shaw, R. A., Kulmala, M., and Siebert, H.: Observations of new particle formation in enhanced UV irradiance zones near cumulus clouds, Atmos. Chem. Phys., 15, 11701-11711, https://doi.org/10.5194/acp-15-117012015, 2015.

Wex, H., Neusüß, C., Wendisch, M., Stratmann, F., Koziar, C., Keil, A., Wiedensohler, A., and Ebert, M.: Particle scattering, backscattering, and absorption coefficients: An in-situ closure and sensitivity study, J. Geophys. Res., 107, 8122, https://doi.org/10.1029/2000JD000234, 2002.

Wiedensohler, A.: An approximation of the bipolar charge distribution for particles in the submicron size range, J. Aerosol Sci., 19, 387-389, https://doi.org/10.1016/0021-8502(88)90278-9, 1988.
Wiedensohler, A., Birmili, W., Nowak, A., Sonntag, A., Weinhold, K., Merkel, M., Wehner, B., Tuch, T., Pfeifer, S., Fiebig, M., Fjäraa, A. M., Asmi, E., Sellegri, K., Depuy, R., Venzac, H., Villani, P., Laj, P., Aalto, P., Ogren, J. A., Swietlicki, E., Williams, P., Roldin, P., Quincey, P., Hüglin, C., Fierz-Schmidhauser, R., Gysel, M., Weingartner, E., Riccobono, F., Santos, S., Grüning, C., Faloon, K., Beddows, D., Harrison, R., Monahan, C., Jennings, S. G., O’Dowd, C. D., Marinoni, A., Horn, H.-G., Keck, L., Jiang, J., Scheckman, J., McMurry, P. H., Deng, Z., Zhao, C. S., Moerman, M., Henzing, B., de Leeuw, G., Löschau, G., and Bastian, S.: Mobility particle size spectrometers: harmonization of technical standards and data structure to facilitate high quality long-term observations of atmospheric particle number size distributions, Atmos. Meas. Tech., 5, 657-685, https://doi.org/10.5194/amt-5-657-2012, 2012.

Wu, Z. J., Poulain, L., Henning, S., Dieckmann, K., Birmili, W., Merkel, M., van Pinxteren, D., Spindler, G., Müller, K., Stratmann, F., Herrmann, H., and Wiedensohler, A.: Relating particle hygroscopicity and $\mathrm{CCN}$ activity to chemical composition during the HCCT-2010 field campaign, Atmos. Chem. Phys., 13, 79837996, https://doi.org/10.5194/acp-13-7983-2013, 2013.

Zarzycki, C. M. and Bond, T. C.: How much can the vertical distribution of black carbon affect its global direct radiative forcing?, Geophys. Res. Lett., 37, L20807, https://doi.org/10.1029/2010GL044555, 2010.

Zaveri, R. A., Barnard, J. C., Easter, R. C., Riemer, N., and West, M.: Particle-resolved simulation of aerosol size, composition, mixing state, and the associated optical and cloud condensation nuclei activation properties in an evolving urban plume, J. Geophys. Res.-Atmos., 115, D17210, https://doi.org/10.1029/2009JD013616, 2010.

Zhang, Q. and Thompson, J. E.: Effect of particle mixing morphology on aerosol scattering and absorption: A discrete dipole modeling study, GeoRes. J., 3, 9-18, https://doi.org/10.1016/j.grj.2014.07.001, 2014. 